\title{
The Mass Impact of Videogame Technology
}

\author{
THOMAS A. DEFANTI
}

Department of Electrical Engineering and Computer Science
University of Illinois at Chicago
Chicago, Illinois

1. Introduction . . . . . . . . . . . . . . . . 93

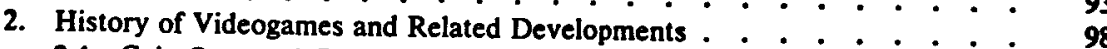

2.1 Coin-Operated Games. . . . . . . . . . • • • • • • • 98

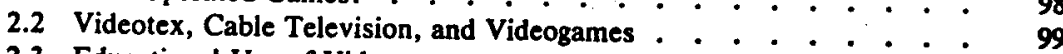

2.3 Educational Use of Videogames

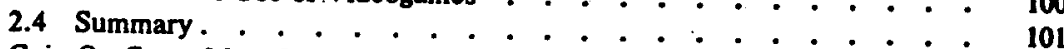

3. Coin-Op Game Manufacturers. . . . . . . . . . . . . . . . . . . . . . . . . 101

4. Types of Games . . . . . . . . . . . . . 103

5. Market Considerations . . . . . . . . . . . . . . . . . . . . . 108

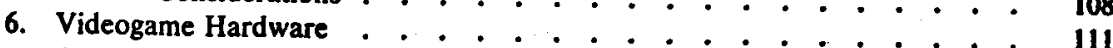

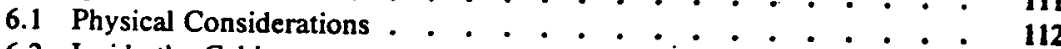

6.2 Inside the Cabinet . . . . . . . . . . .

6.3 Computer Graphics Display Hardware . . . . . . . . . . . . . . . . . . . 116

6.4 16-Bit Microprocessors . . . . . . . . . . . . . . . 121

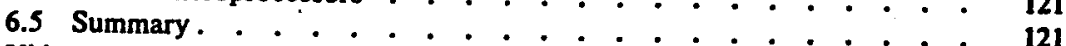

7. Videogame Software. . . . . . . . . . . . . . . . . . . . . 122

- 7.1 Game Design . . . . . . . . . . .

7.2 The Player . . . . . . . . . . . . . . . . . ..${ }^{\circ} 122$

7.3 Strategy . . . . . . . . . . . . . . . . . . . . . . . . .

7.4 Animation . . . . . . . . . . . . . . . . . . . . . . . . 125

7.5 Language and Development Systems .

7.6 Development Systems and Artist Work Stations . . . . . . . . . . . . . . 130

7.7 Sound in Videogames. . . . . . . . . . . . . . . . . . . . . 132

7.8 Summary. . . . . . . . . . . . .

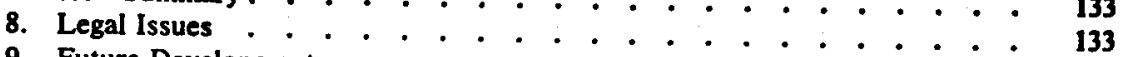

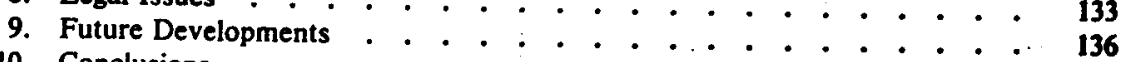

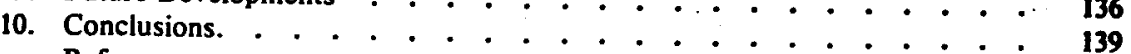

References . . . . . . . . . . . . . . . . . . . . . . 139

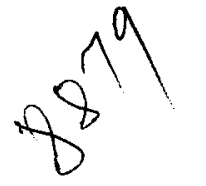

Copyright 01924 by Acedemic Press, Inc. All rights of reproduction in any form reserved. ISBN 0-12-012123-9 
appeared and touched our lives. It has largely eliminated people's fears of computers, has bypassed language, cultural, and age barriers, and has made participatory fantasy available to anyone with twenty-five cents. When measured by traditional entertainment industry methods, the box office take of this form, the videogame, has ranged between $\$ 5$ and $\$ 12$ billion a year, depending on whose figures you trust and how much income goes unreported. Assuming $\$ 10$ billion a year, and throwing in the $\$ 3$ billion home videogame business, this new use of interactive computing generates income three times that of the music (record) business, three times Hollywood, and exceeds the commercial billing of all the major television networks combined. Thus, the economic force behind videogames is greater than that behind the dominant form of communication in our culture, the form which elects presidents and dictates our desires. This force thrives on new entertainment ideas and is mercilessly pushing the state of the art in hardware, software, and interaction techniques.

Because it is reasonable to assume people will be communicating with computers through inexpensive interactive graphics screens, it makes sense to study technological progress and the conceptual implications of the videogame past, present, and future. This discussion will focus on the hardware, software, marketing, legal aspects, and future of coin-operated arcade videogames ("coin-op" or "arcade" games). Anyone interested in teaching, technology, interaction, nonverbal or postverbal communication, or hardware or software should be developing an awareness of the underlying design of these machines.

Given the extreme market pressures to come up with "hit" games, this is a very special time for creative people in low-end computer graphics. Increasingly larger development budgets are accelerating the creation processes of very-large-scale integrated (VLSI) circuit custom and semicustom chips and specially configured bit-slice processors. The growing awareness of the importance of aesthetics and software is providing great opportunities to the creative game designers. Interactive graphics has been accepted into our lives considerably faster than was interactive audio (the telephone), which, like graphics, was initially envisioned as a tool primarily for business use. About 12 million home games are attached to television sets and well over a million arcade games are available to the public in various locations.

The home game is a phenomenon somewhat different from the coin-op game. Many-of the home games can be upgraded to simple home computers with the addition of a keyboard and a BASIC language module. So far, at least, the games on home machines are almost completely derivative of the coin-op games in every way but marketing. Many game pro- 
grammers prefer designing the home game because cartridge development is suited more to small companies and individual authorship than is the design of an entire machine, and because the home game (as compared with coin-op games) has much more educational potential. This discussion, however, will concentrate on coin-op games because, costing 10-20 times as much as home games, they continue to define the state of the art in personal interactive graphics.

Coin-op videogames are not much like the computers found in the office. They are not used as a condition of employment, but for entertainment. They do not emulate a former activity in a cost-effective way, normally a prerequisite for justifying computer use. Videogames do not have rotating magnetic media storage such as disks or tapes because they do not store user-supplied information. They have no keyboards and no printers because they are nonverbal. They are, however, extremely user
friendly.

Another crucial difference is that coin-op games are intended to be disposable. The videogame industry is currently structured to depend on obsolescence, as is any entertainment or consumer industry, and is now suffering from a reluctance on the part of owner/operators (those who buy games and/or operate arcades) to dispose of a $\$ 3000$ machine whose only problem is being out of vogue.

The life of a videogame is measured in months. Good games pay back their purchase price in under 6 weeks, the rest of the lifespan representing pure profit for the owner/operator. Poor games do about as well as poor movies, and the same is true of old games, with the exception that there is no equivalent to television reruns. The hardware of a videogame will continue to operate for 10 years, at least, but no one supposes PAC-MAN will play in 1991, nor will people put quarters into two-dimensional, lowresolution, 16-color machines no matter what the game. (Contrast this with the fondness accorded to old pinball machines!) This is one industry in which the end user (not the manager or vice-president) votes directly, a first for the hardware/software world.

Videogames could not have satisfied the voracious and capricious appetites of game players without the amazing advances in microprocessor technology and the reductions in memory costs. At one point, Atari used more read-only memory (ROM) than all other companies in the world combined (Tekla and Wallich, 1983; Tekla et al., 1982). Williams' SINISTAR (Fig. 1) has $68 \mathrm{~K}(\mathrm{~K}=1024)$ bytes of random-access memory (RAM) and over 52K bytes of ROM. In 1973, RAM slower than that used in today's microprocessots cost about $\$ 100 /$ kilobyte in large quantities. Current prices for dynamic: RAMs are about $\$ 700 /$ megabyte, with ROMs about half as expensive, better than two orders of magnitude in cost. Such 


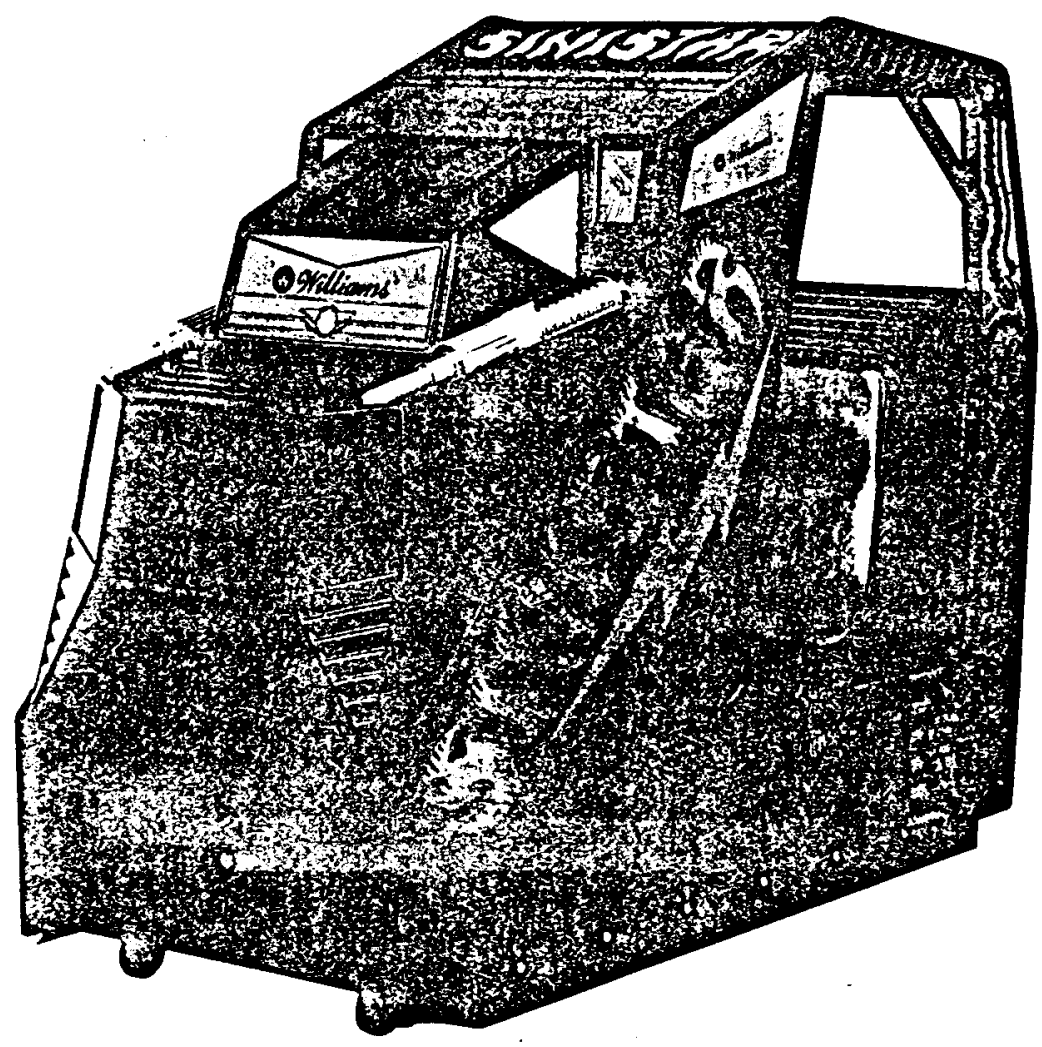

Fig. 1. Williams' SINISTAR.

a change in magnitude, let us not forget, exceeds the difference between the speed of walking across the country and flying, with all that this implies, yet it has come upon us much more rapidly.

The computing power of microprosessors and custom logic have undergone similar improvement and cost reductions. Ten years ago there simply did not exist commercially available equipment which could put out real-time animation on a color television set. Now, of course, such devices with built-in joysticks and keypads are available for under $\$ 100$, with software included.

The entire ivideogame industry, until now, has acted quite independently from the mainstream computer trade. There has been no formal 
involvement with professional and educational societies such as IEEE or ACM. The Japanese Fifth Generation Computer Project (ICOT) has many computer industry supporters, none of which is a coin-op videogame manufacturer. Trade secrecy is heavily enforced and publishing by researchers is not considered relevant to the health of the arcade game. Videogame conferences have mainly concerned social effects and the problems of programmer/artists and management, not the technology.

Another unusual aspect of the coin-op business is the conspicuous absence of advertising. Coin-op games, of course, are quite generically different from print or even television, thus successful communication of the desirable aspects is difficult. The few promotion attempts so far, and the ads for home videogames, give truly new meaning to the term "deceptive advertising." Interactive play is by far the most important aspect of videogames, and it is communicated by completely nonverbal means in the arcades. The print ads stress still graphics, usually artists' interpretations of the game scenes, and are interpreted by the very sophisticated game-playing people as being completely irrelevant. It is easy, on the other hand, for someone who has not played videogames to dismiss them on the basis of the advertising. An unfortunate result of all this is the nearly complete lack of marketing analysis which usually comes as part of the ad campaign planning and follow-up.

However, videogames have seriously and irreversibly affected the computer industry. Game players (mostly adolescents and people in their twenties) are unlikely to react favorably to a half-million-dollar office automation system that does not have joysticks, is not user friendly, and does not offer the simple high-level programmability offered by the simplest home game with BASIC. Color animation, which allows a much closer matching of human and computer bandwidths, is now expected from computing devices. Availability of intense, nonverbal, two-way communication is now taken for granted, spelling an early end to complete reliance on the unpleasant exercise of reading all day from a video display terminal. To a certain extent, we are very fortunate that computer graphics, unlike television, is incapable of transmitting "talking heads" very well, because that would be too easy a misuse of the power of the medium, one to which edućational television has defaulted.

In not having a previous medium to emulate, videogames have had to create a new way of communicating. They are truly a new medium. Maturity, still a long way off, will spawn some new form of what may be called interactive literature. Now, however, we can observe an industry in early infancy, struggling and trying to be part of our lives. It is a special time to watch, play, and enjoy. 


\section{History of Videogames and Related Developments}

In a sense, this section presents what is really a prehistory in that the actual development of games is discussed in Section 6.

\subsection{Coin-Operated Games}

The coin-operated amusement industry includes the kiddy rides found in supermarkets, jukeboxes, coin-operated pool tables, weight and fortune-telling machines, and the other devices found in penny arcades. One of the best surviving penny arcades is found on the beach in Santa Cruz, California, where machines still using pennies and nickels can be played alongside the newest videogames. Another old-style arcade is part of the oceanfront complex slightly up the coast from Golden Gate Park in San Francisco.

Coins also operate slot machines and the newer video roulette and blackjack games. These devices appeal to a completely different clientele than do videogames, even in places where they exist side by side such as in Las Vegas supermarkets and gas stations.

Early coin-operated electronic games include the familiar bear with the midriff photocells which are shot at with a beam of light. Each hit causes the bear to change direction and increases the score.

RED BARON, a game designed by Dave Nutting Associates, appeared in about 1970. It had a rotating disk full of film frames that were projected onto the screen, with eight different poses for each aircraft, depending on the player's movement of a joystick. Holes in the disk, coupled with photocells, allowed matching of the trigger pull with aircraft location, providing a scoring mechanism. This game, completely relay controlled, featured light tracers projected by a moving mirror. The last of this genre appeared in 1978 as Namco's SUBMARINE, an elaborate game full of motors, mirrors, and film transports. It was soon replaced by its video equivalent, Bally's SEAWOLF.

Pinball machines, until 1974, were also relay driven. They were a holdout of World War II technology of which only a few companies, mostly in Chicago, could still claim mastery. In 1974, Jeff Frederiksen, of Dave Nutting Associates, developed FLICKER for Bally. It was an Intel 4004 microprocessot-based game. Emerging videogame technology quickly replaced the pinball gong sound effects with synthesized sounds. Special scoring features and multiplayer options not feasible with relays were added. In last-ditch efforts to save the pinball game, designers added multilevel, multiball games with voice (Bally's XENON), extra controls (Williams" "magna save" feature in BLACK KNIGHT), and videogame 
screens (Bally's BABY PAC-MAN). Until SPACE INVADERS, a good game nun was a few thousand machines. It is a measure of the growth of the industry that a game selling 15,000 units is considered marginal today.

Atari, which was put together after Nolan Bushnell's videogame proposals were rejected by Bally, had no gambling or pinball reputation to live down and may be fairly credited for the cleaner image attributed to videogames. PAC-MAN also helped convince the village elders that videogames were like pinball if and only if the owner/operators maintained pool hall-like environments. Pizza parlor game centers and arcades in shopping malls and convenience stores have successfully provided safe and relatively clean locations for game play.

\subsection{Videotex, Cable Television, and Videogames}

"Videotex" is the generic name for two-way or one-way text transmission using television screens as receivers. "Teletext" generally refers to one-way (broadcast) videotex, and "viewdata" refers to two-way videotex. Brand names include Antiope (France), Prestel and Ceefax (Britain), Telidon (Canada), and Captain (Japan). These systems were all designed with consideration to the cost of memory and microprocessors 8 years ago and are nearly completely devoid of interactive graphics capability. The user cannot program the end device, nor can these devices execute transmitted programs with loops, thus denying access to what is arguably the best idea of the twentieth century, the stored-program looping computer. The Telidon system is the most evolved protocol in that it can construct geometric shapes of resolution matching the end device's capability, although photorealișm is still extremely inefficient to transmit. All the other systems offer, at most, alphamosaics for graphics, a way of creating pictures by defining special characters in patterns.

Videotex is based on data presentation, not action. One-way systems, with the exception of those providing captioning for the hearing impaired, have failed in all home test markets. As Jane Veeder, interactive computer artist, points out, what good is a six-page zucchini recipe coming across on your television? You cannot copy it down fast enough, videotaping it would require at least 10 seconds warning that it is coming, and taping everything does not work because there is no indexing for retrieval of the information. Of course, people do not go to movies to read from the screen either.

Two-way systems suchitas Warner's QUBE in Columbus, Ohio, have done somewhat better, although such systems provide access comparable to 1.0000002-way access, allowing the user to transmit back only a bit every couple of seconds. The unavoidable conclusion drawn after several 
years of cable television availability is that if good antenna reception is achievable, cable television is not worth the cost. Even with systems providing two-way access, searching databases is not perceived as entertaining by the general public.

As a further point, according to Nicholas Negroponte (1983), the one thing all these systems have in common is the illegible character font they use. The standard for videotex prescribes $5 \times 7$ dot-matrix characters at a resolution barely readable on the average television set. (The photos often seen of videotex are taken off direct-drive red-green-blue (RGB) monitors, not cable-fed television sets, by the way.) Researchers in Negroponte's lab at the Massachusetts Institute of Technology have shown that 2 bits/pixel of grey value is necessary for good legibility. It is outrageous to expect people to read $5 \times 7$ type all day long on computer screens, given 400 years of development of typefaces designed for easy reading.

Home videogames have been experimentally hooked to cable systems for two-way access of games (Smith, 1983). Cable head-end operators, however, are not inclined to maintain databases, even of videogames, because the investment capital is not currently available to cable television and the payoff is uncertain. In addition, two-way cable is quite rare, despite the theoretical desirability.

Videogames, at least current ones, are technologically possible because they have very modest data storage requirements. Nonpicture data in a game are almost nonexistent; videogame ROMs are virtually all instructions and patterns for visuals. Videotex systems, on the other hand, need vast amounts of data to be worthwhile. They have all the worst problems of computing to solve: inadequate and boring data, poor presentation, slow access, expensive phone line charges (destined to get much worse), and no local processing. It is no surprise that there are a dozen million videogames in United States homes, yet videotex systems have had penetration only in countries where their existence is federally mandated.

\section{$\therefore \quad 2.3$ Educational Use of Videogames}

Although the application of low-end interactive graphics technology to education is obvious; many factors have kept it an idea before its time. It is still far less expensive to hire a teacher than to provide and maintain a classroom full of home computers, even if software were free. The market for educational software is still tiny and is constrained to operate largely within the chanriels of conventional textbook production. Software authoring does not count as publishing in academia, thus one part of the academic reward system is missing. 
The future is nevertheless bright. More and more educators are becoming computer literate. A shortage of teachers is once again threatening the elementary schools and it will be easier to use computers than suffer through the totally out-of-sync training of new teachers. It takes a year or two to train a computer, but 5 years to produce a teacher, once the need is perceived and a solution funded. Moreover, children like computer games, even educational ones. Home computer systems are becoming more prevalent, thus part of the delivery system is actually in place, awaiting educational legitimization as calculators once did.

Never, however, look to the coin-op industry for education. The arcade videogames are entertainment; any educational aspect which might be extrapolated is only in the imagination. In all of the interviews conducted in the process of researching this article, not a single person in the coin-op field was able to give any answer to the question "What do you think this technology means to the future of education?" It is simply not a subject of much discussion, even now.

\subsection{Summary}

Even though they share the technology of information systems, videogames are generically quite different. As an entertainment medium, they can teach us about the presentation of information in nonverbal ways that have the potential of involving people who have no desire to pay to read from television screens. It will certainly take a new awareness to elevate the videogame from its current "shoot 'em-up" plateau to our dreams of computer-assisted instruction, but it may be the easiest path the technology has to offer.

\section{Coin-op Game Manufacturers}

There are currently several dozen manufacturers of arcade videogames worldwide. However, as in the automobile in tus iry, it makes sense to talk of the major domestic companies (Atari, Inc., Bally Manufacturing Corp., and Williams Electronics, Inc., in alphabetical order) and the Japanese companies Namco, Nintendo, Sega, and Taito. Of these, only Atari also makes home games. (Until recently, Bally manufactured all of its videogames under its Midway division name.)

Atari and Bally routinely license games from Namco [POLE POSITION (Fig. 2) and PAC-MAN] for manufacture in western markets. The game credited with the spread of the videogame craze, SPACE IN- 


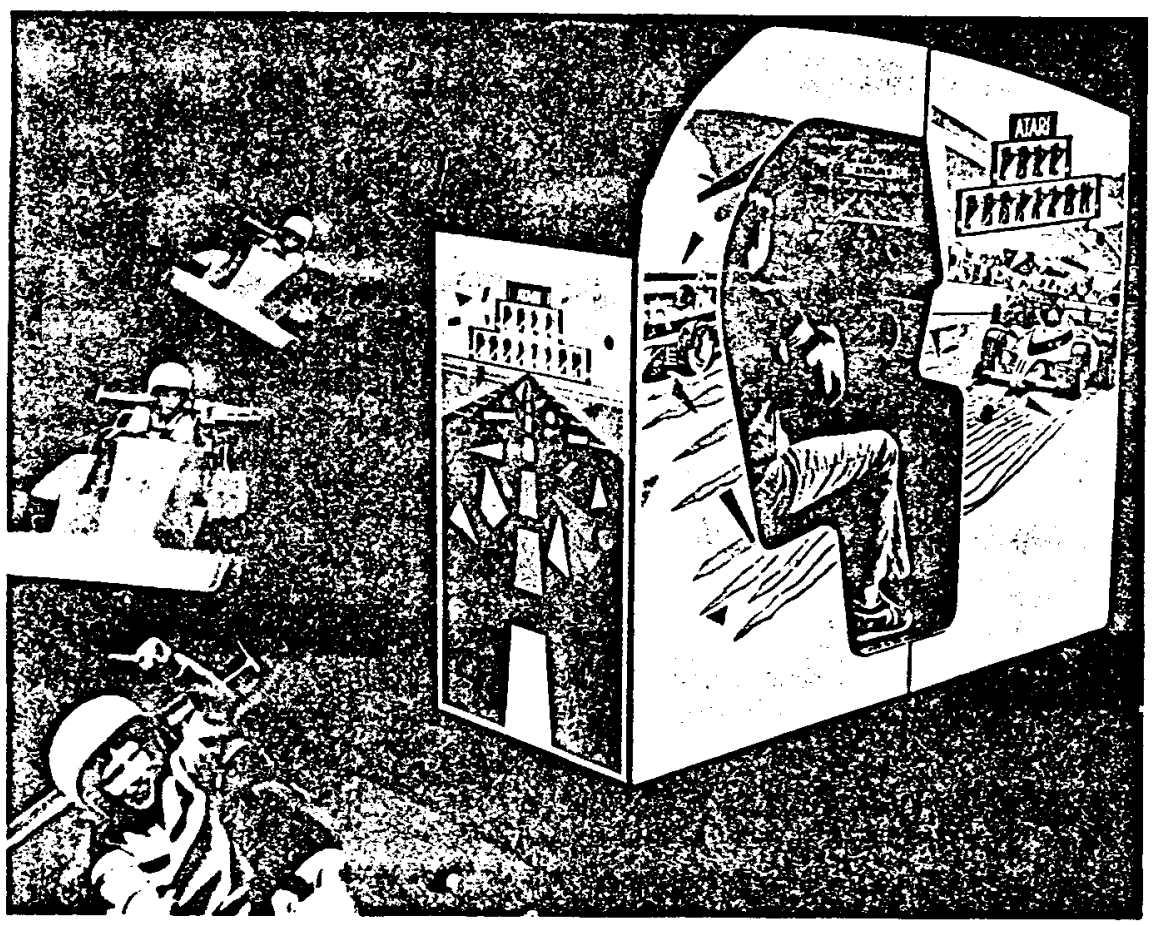

FIG. 2. Atari's POLE POSITION. Pole Position is engineered and designed by Namco, Ltd.; manufactured under license by Atari, Inc. Trademark and copyright, Namco, 1982.

VADERS, was a Taito game, built here by Bally. Nintendo, of DONKEY KONG fame, and Sega (ZAXXON, CONGO BONGO) market their own games through United States divisions.

Bally and Williams developed videogames largely as an expansion of their pinball business. Atari, starting in videogames, attempted pinball production but abandoned it. The pinball production lines have all but halted, having been superceded by the less kinetic but more conceptually sophisticated videogames. In many people's opinion, this may be one of the most negative side effects of videogames, in the final analysis.

Figures $3 i 9$ are photographs of products representing the big three manufacturers and are not meant to be an exhaustive sample. In fact, the publicity divisions of these companies do not maintain photo files for past products and cọuld send glossies only for current machines. There is not much respect for history in this industry. There is not even an informal museum of videogames and there is no effort by manufacturers to preserve working models. Games are copyrighted as audiovisual works, but 
the Library of Congress does not accept the actual machinery. Rather, a videotape of the game in operation is deposited.

The videodisk game has given rise to several new companies, Cinematronics being the current leader (Eurell, 1983). Quite a shakeout of videogame manufacturers occurred in 1983 . The years 1984 and 1985 should be quite exciting for investors, programmers, and designers alike.

\section{Types of Games}

In any new field, a jargon quickly develops among the practitioners. Existing words are given new meanings and new contexts are created.

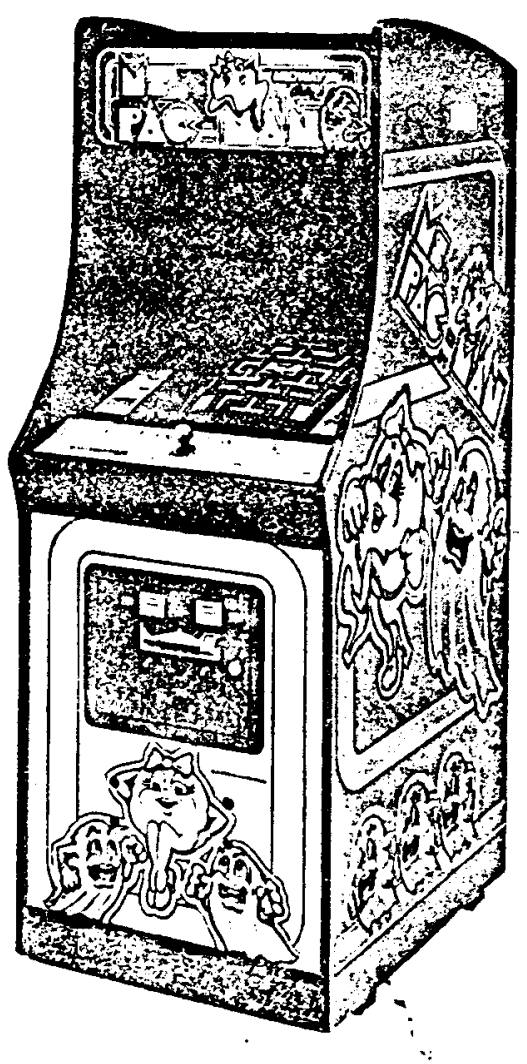

Fic. 3. Bally's Ms. PAC-MAN.

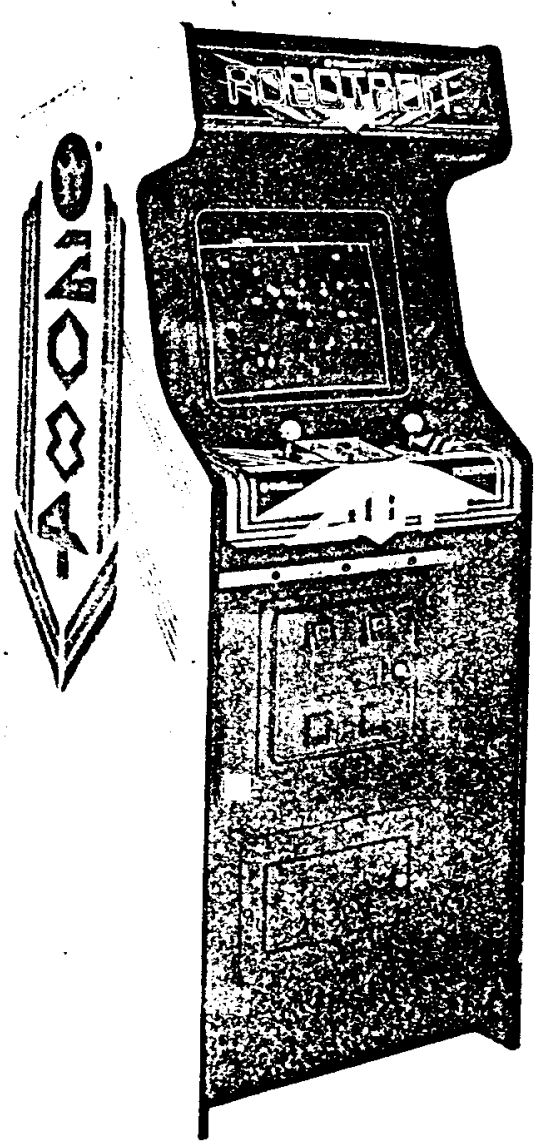

Fig. 4. Williams' ROBOTRON 2084. 


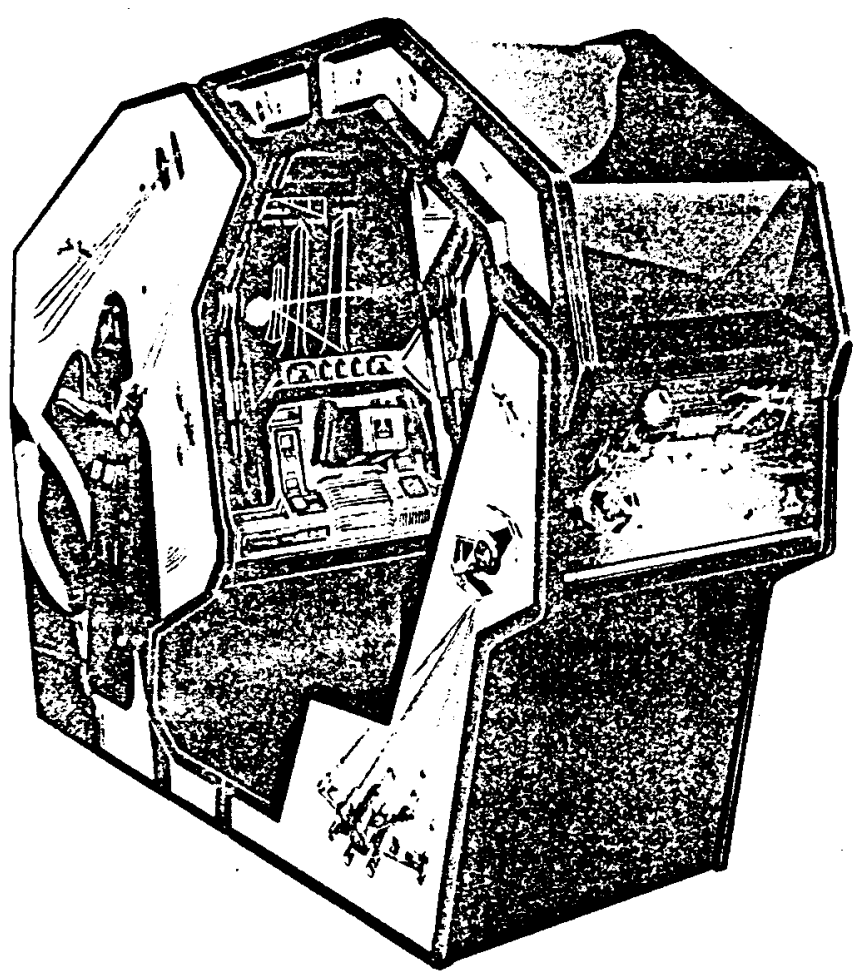

FIG. 5. Atari's STAR WARS. Copyright 1983, Lucasfilm, Ltd., and Atari, Inc. All rights reserved. Trademarks of Lucasfilm, Ltd. used by Atari, Inc. under license.

There are many ways to differentiate one videogame from another. The discussion in this section will attempt to set forth the currently important distinctions.

Critical to this discussion is the difference between coin-operated arcade games and home games. The former cost about $\$ 2800$ currently and run on quarters, somewhere between 20 and 50 billion of them per year depending on whom you believe. "Owner/operators" buy or lease games in "locations" which are either "arcades" (game parlors existing for games only) or stores which sell something else in addition. Coin-op games are found on navy ships and in national parks (Adams, 1982) and are very popular even in Disneyland (!). Game machines, by design, have not been amenable to change of software, although this is starting now. The manufacturers actively encourage total and carly replacement. The 
top 10 games average $600-1000$ plays per machine per week, therefore earning from $\$ 150$ to $\$ 250$ (Video Games, 1983, p. 82; Playmeter, 1982, p. 16); one fifty-cents-per-play game (Atari's POLE POSITION) has been taking in $\$ 450$ per week. Cinematronic's DRAGON'S LAIR, a new videodisk-based game, also fifty cents per play, has reported earnings of $\$ 850$ per week. There are well over a million coin-op machines in locations.

Home games range in price from $\$ 50$ to $\$ 300$ and they are usually attached to a color television set. About 12 million of these games have been sold to date; in 1982, $\$ 3.5$ billion was spent on consoles and game cartridges. Many home games accept keyboard attachments which trans-

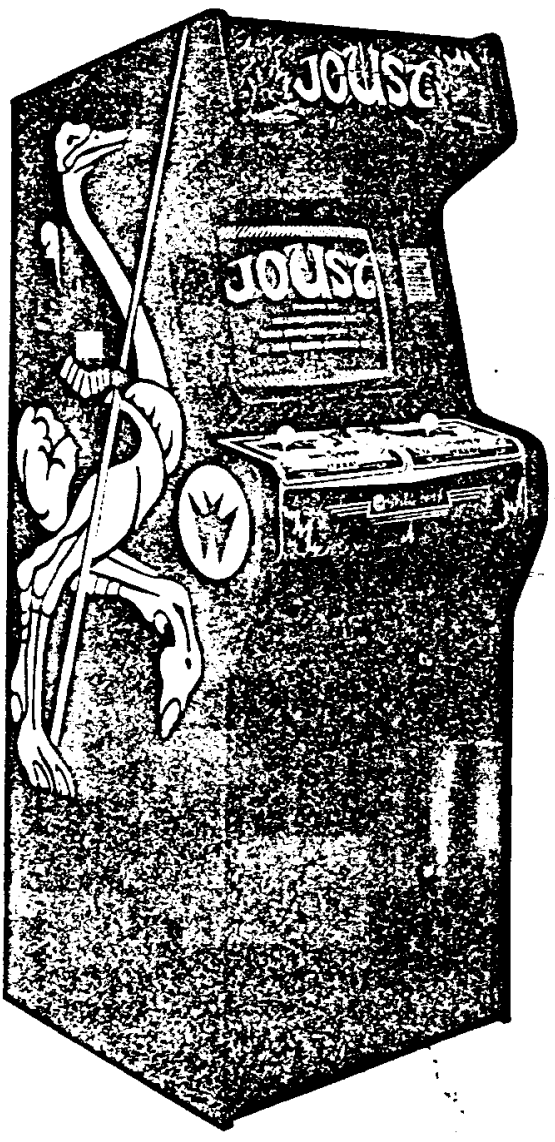

FIG. 6. Williams' JOUST.

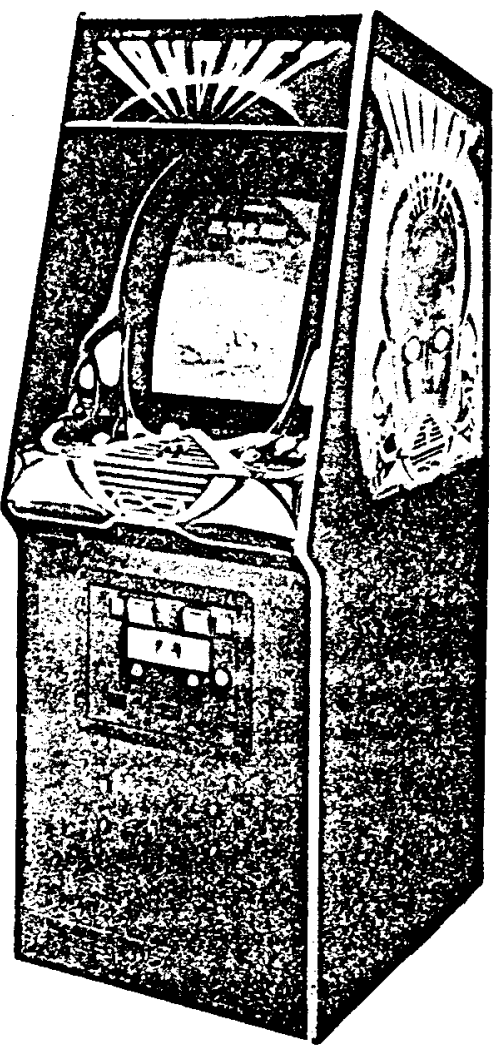

FIG. 7. Bally's JOURNEY. 


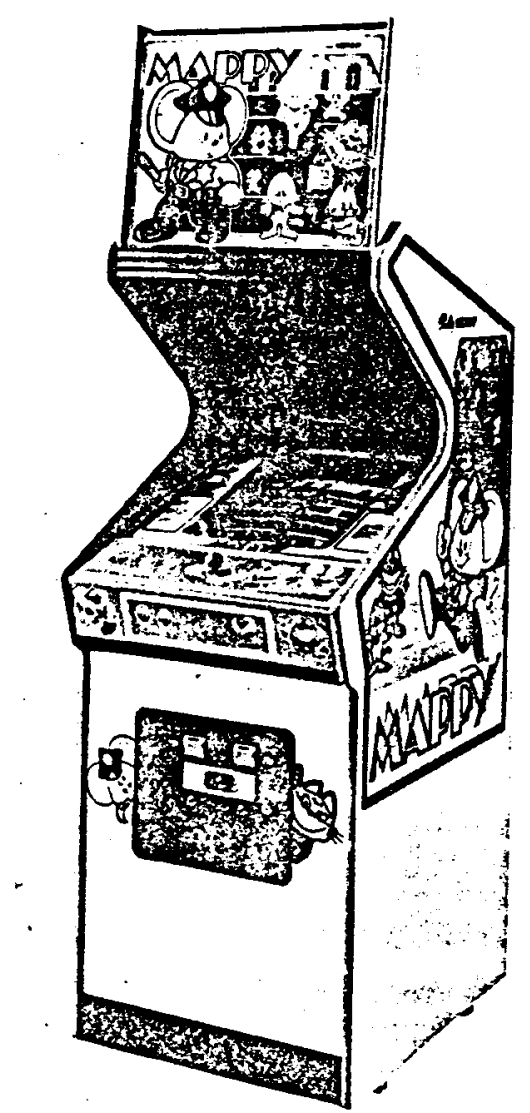

FIG. 8. Bally's MAPPY.

form them into home computers running BASIC. Of course, there are also home computers which play games stored on a floppy disk.

One way to categorize coin-op games is by the number of players. Oneand two-player games exist, and although all games allow players to take turns, two-player games allow both to play at the same time: against the machine, against each other, or both. Except for cocktail table games (see Section 6), most games are played solitarily. One-player games are easily $95 \%$ of the market. On the other hand, it is really boring to take turns with a good player. on a one-player game, thus two-player games have their socially redeemìing aspects.

An important dividing line is drawn between games that appeal to casual players and those designed for the skilled player. Bally games seem 
to be in the former category, marked by ease of control and thematic cuteness, whereas Williams games are often preferred by the enthusiast, being fast, tricky, and occasionally absurd, but not cute. Atari games span the gamut, each game being quite different from all the rest. Nintendo, of DONKEY KONG fame, imports cute games from Japan that also appeal to a broad spectrum of players. Owner/operators are very skilled at monitoring the interest of their clientele given that the vote comes in every day
in quarters.

Games can be described further as cute, funny, deadly, funny cute, and funny deadly. Identifying members of the first four categories is an exercise left to the reader. ROBOTRON 2084 (Williams) is a funny-deadly game featuring "your family": Daddy, Mommy, and Mikey. A brain

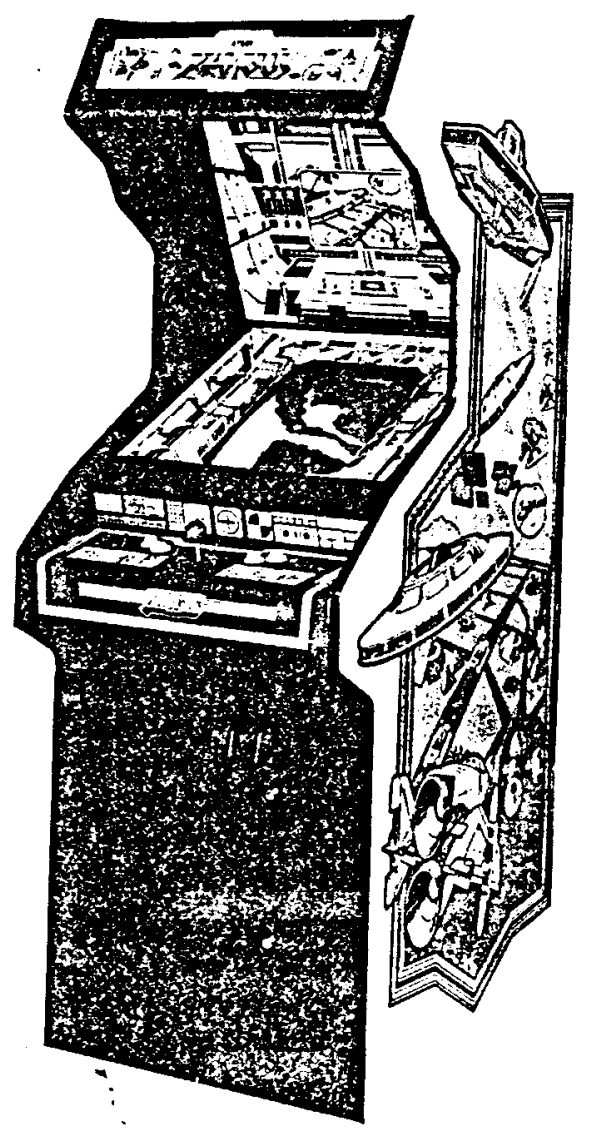

FIG. 9. Atari's XEVIOUS. Xevious is engineered and designed by Namco, Lid.; manufactured under license by Atari, Inc. Trademark and copyright Namco, 1982. 
appears every so often to pick up family members and reprogram them into enemies by shaking them. Funny deadly is ideally appealing to the sense of absurdity with which teenagers continually perceive the world around them.

Persons who wish to save the world from videogames often complain about the prevalence of death and destruction. Death, being a binary concept (you are dead or not dead), well matches the processing power left over in an 8-bit microprocessor after the animations are managed. Shooting is a "very obvious concept" (Murphy, 1983) and seems to be greatly appealing to dramatists, dart players, hunters, and children, as well as to videogame players. On the other hand, PAC-MAN is considered nonviolent because he eats instead of shoots, and even when he gets caught by a ghost and disappears, death is not the apparent cause because points are not awarded. Car-racing games, as in real life, have a distinct death component; only those encouraging the death of pedestrians seem to get universal criticism.

Another important distinction is first person/third person. The older games and many current ones have the player control a "ship" or other character that can be seen in the playfield. These are called "third-person" games. First-person games give the feeling of looking out the windshield into a simulated-perspective projected space and are considered much more exciting. Atari's BATTLEZONE is a good example of a firstperson game, whereas their POLE POSITION has some elements of both types.

Other dividing differences such as raster/vector, color/black and white, and player control mechanisms are covered in Section 6. Some new concepts with potential are given at the end of Section 9.

\section{Market Considerations}

The "market" is not usually considered in a discussion of the technological advances of computing, but, in this case, it is clearly the driving force behind the progress in low-end technology. Growth rates of $80 \%$ per year were common until 1983, when things turned around. It is worth studying how marketing analysts have dealt with something they clearly did not understand at first, how they made a couple of good guesses, and how they now realize how much they still do not understand. Nouveau experts analyzte every blip, as they must in an entertainment market equivalent to commercial television. Some clear trends have emerged and these will be presented here without much in the way of gratuitous speculation. 
A game retailing for $\$ 2800$ has about $\$ 900$ in hardware, less than half of which is computer circuits and chips. It currently costs about a quarter of a million dollars to bring a "shoot 'em-up" game to test market, maybe $25 \%$ going to programmer salaries. The rest is devoted to hardware development, market studies, artwork, and testing. Add to that a million dollars for the first production run of a 1000 games. Videodisk-based games are expected to cost 1-2 million dollars per game for software and artwork alone, and once "talent" gets involved, expect real Hollywood film-type budgets. Gross manufacturing profits approach $\$ 1000$ per game, thus a 100,000 -unit run might well net $\$ 100$ million gross profit. Similarly, a respectable game running 20,000 units can gross $\$ 20$ million. Furthermore, the royalties for spin-off products using PAC-MAN characters are comparable to the royalties for Star Wars movie paraphernalia. Fleer Corporation recently paid Bally $\$ 600,000$ for 1 year's pleasure of selling PACMAN candy (Electronic Fun, 1983, p. 98). Another lucrative trade is licensing to the home videogame market.

Manufacturers of videogames also pay out royalties, ranging from a few to $10 \%$ in extreme cases. A fully designed game from Japan, such as POLE POSITION (Namco), will command a high royalty. Producers of movies such as TRON (Disney) require a cut for use of their "property," as do owners of more conventional characters such as Popeye and Buck Rogers. The game designers, if they are in a good bargaining position from having a strong track record, will get a percentage as well.

However, once royalty negotiations are dealt with, there is no discernible, mature, decision-making process operating in the coin-op videogame field. PAC-MAN was not popular in Japan (where it was called PUCKMAN) and did not do well at first in the United States. Ms. PAC-MAN, selling 115,000 games in the United States, where it was designed, did not sell in Japan. KICK, a Bally game with strong graphics, novel concepts, and even the appearance of PAC-MAN himself at crucial times, had a very short run. Even games at the top of the charts in earnings per machine do not necessarily sell well; there is currently a generally perceived glut in the arcade machine market.

Before examining why saturation has occurred, let us look at some parameters. A player gets 90 seconds or less to be convinced to put a second quarter in. Dave Nutting (a head videogame designer for Bally) often says it is no triçk to get someone to put one quarter into a machine. The second quarter is the tough one. (On a related theme, Dick Ainsworth, a designer for home computer games, says that if you do not think videogames are special, you just try sometime to get a quarter or two out of those teenagers hanging out on the street corner.) A game that is too fast at first will repulse casual players, who, for the first time in 
computing, have to learn the principles of operation for fifty cents or they go away. Of course, people learn by watching others play in arcades and even on television (Schuler, 1983). Many buy books on how to improve their game, just as they do for any sport. But the bottom line is really the first quarter or two and how rewarding the experience is, given that, to top it off, people will not read the instructions under any circumstances.

Considerable attention goes into the "attract" mode, the animated sequence the game goes through when no one is playing. It is supposed to entice, teach the game, and convince a potential player to put in a quarter. It is also called the "shill," a reference to the carnival employee who walks around with the giant stuffed panda to convince people that winning one of those things is possible. The shill teaches far better than the written instructions.

Depending on whom is believed, the average player devotes half an hour a week (Adamo, 1983b) or 6 hours a week (Krier, 1983) to playing, which translates into spending from $\$ 1$ to $\$ 30$ a week. Good players get 35 minutes for a quarter, a time set by extensive prerelease testing. It takes about $\$ 20$ to $\$ 50$ to get good at a new game (Skow, 1982), costing more than going to the movies but less than most equipment-intensive sport rentals.

The coin-op industry does not advertise at all compared to other entertainment media. Only a few television ads have been run so far, one created by Magi for Sega's ZAXXON (Magi, 1982), and one for Atari's XEVIOUS. It is hard to deny that indeed a powerful force is communicating the desirability of playing coin-op machines to players, one that is outside the normal advertising channels. Or is it that advertising cannot communicate the appeal in nonfatuous ways? It is, in any case, encouraging to see youngsters and adults voting with quarters for their favorite technology, unswayed by media hype. People rarely get to affect a market so directly.

So why the current glut of games? There are several opinions. Arnold Greenberg, the president of Coleco, an aggressive home game manufacturer, says of the coin-op games market: "There's been a proliferation of newer machines, but they've been unable to gain a foothold because the hits of yesteryear are such hearty perennials. Another reason for its weakness is that there are now many coin-op hits available in home versions." (Trakin, 1983).

Robert Mullane, president of Bally, has stated that "we ignored the long-term future of this industry.... We have a multibillion dollar business at retail with probably the skimpiest market research of any industry in the world. ... Bally has increased its spending on research and develop- 
ment in an attempt to alleviate the boredom associated with current games." (Playmeter, 1983, p. 18). These are strong words.

On the other end of the power structure, Tim Murphy, independent games consultant, says of management:

\footnotetext{
Management wants games out too fast, six to nine months. Everyone wanted to cash in on the boom and they got stuck with junk they now have to make pay off. Superficial observations like 'color equals good' caused the wrong things to be pushed. Many games with great color graphics are like a ride at kiddyiand, you just sit there and watch. Programmers and designers work under middle management, not top management, so there is no effective communication, just politics.
}

He agrees with the home market observation: "If something looks like an Atari 2600 home game, why spend money to play it in an arcade?" (Murphy, 1983).

Eugene Jarvis, the legendary programmer of DEFENDER, says

Many of the throng stand mesmerized before the altars of last year's favoritesAsteroids, Pac-Man, Defender and Bezerk. But there are also some new faces in the crowd with close family ties-Space Duel (Asteroids III), Ms. Pac-Man, Stargate (deluxe Defender), and Frenzy (deluxe Beserk). '82 may weil go down in history as the year of the 'deluxe.' The arcade scene has been beset by more spin-offs, rip-offs, retreads, and cross-pollinations than you can shake a joystick at. 'Is there some kind of corporate conspiracy against originality or could there be some socially redeeming value to this clone onslaught?' I mutter en route to the change machine. [Jarvis, 1982].

The old games often still pay well it seems, so why discard them?

A market exists for the new games in the arcades, of course, but will the convenience stores and other three-machine locations buy new games every 6 months? The upgrade/conversion kit has been a proposed solution, one first fought bitterly by the manufacturers but now considered to be enlightened marketing (see Section 8). Videodisk-based game manufacturers now hope to get buyers by offering the most potential for supporting replaceable software.

In any event, although trimming production considerably, most manufacturers are increasing research funding, a good sign for those who believe in the potential of graphic communication.

\section{i \\ 6. Videogame Hardware}

In the following discussion, videogame hardware will be examined, starting with the cabinet and proceeding inward to the circuits and logic. 


\subsection{Physical Considerations}

The coin-operated videogame currently is available in four physical configurations: full-size upright, mini upright, sit-in, and cocktail table. Games are often manufactured in two or three of these categories, primarily to sell to different types of locations.

The full-size and sit-in models use $19^{\prime \prime}$ monitors and take up the most space. Full-size cabinets are approximately $26^{\prime \prime}$ wide by $34^{\prime \prime}$ deep by 73 " high. They are usually arranged in rows giving each player sufficient room to operate the game without necessarily intruding on the next player's space. These games are operated while standing up; owner/operators often provide stools for children to stand on so they can reach the controls and see the screen. Sit-ins are much larger ( $26^{\prime \prime}$ wide by $64^{\prime \prime}$ high by $48-72^{\prime \prime}$ deep) and require side access to get into, thus they cannot be placed in rows. Thus, although players like sit-ins, floor space considerations limit their numbers.

Mini's use $12^{\prime \prime}$ monitors and are approximately $20^{\prime \prime}$ wide by $24^{\prime \prime}$ deep by $60^{\prime \prime}$ high. Mini's are not placed in rows; rather, they are designed for locations where blending into the furniture is important. They are often finished in simulated walnut instead of the garish motif of the full-sized games.

Cocktail table games ( $32^{\prime \prime}$ wide, $29^{\prime \prime}$ high, 22" deep) are for coffee houses, bars, and restaurants. The controls are usually poorly situated under the glass table top which covers the whole unit. Most cocktail table games are for casual users; their location presumes the players will be eating or drinking some of the time instead of playing. (In Japan, where ubiquitous coffee lounges rent sitting space for the rather expensive price of a caffeinated beverage, cocktail table games have approximately $85 \%$ of the market and are the mainstay of the arcades as well.) Because the player is sitting, the most energetic forms of player expression are not possible, thus the situation becomes much more sedate and acceptable in places where full-size games would be considered intrusive by (some of) the clientele. Children, of course, can more easily play these games because they can kneel on chairs; furthermore, parents can play with them while waiting for a pizza. Cocktail table games have special software/ hardware enabled'to flip the playing screen so that it always faces the current player.

Although the exteriors of the game cabinets are fairly well finished (at least to the axerage mobile-home quality level), the interiors, which few but the ownertoperators ever see, are rather rough. Only a few games even have card racks (just an extra expense, after all). Most machines simply have the power supply and circuit boards screwed to the plywood 
interior of the cabinet. Cable harnesses and buses dangle and stretch midair. Any other manufactured computer system looks neat and tidy in comparison. For videogame machines with a designed life of a year or less, fit and finish is just not a goal.

Videogames cost between $\$ 1700$ and $\$ 4200$ (in 1983). Most are about $\$ 2800$. In a mass-production situation, this means that the hardware and cost to assemble one unit must be less than $\$ 900$. Advertising is nonexistent for all practical purposes and the software costs are spread over a great many machines. Of the $\$ 900$, about $\$ 400$ goes to the electronics and the rest to the cabinet, monitor, coin box, and assembly costs.

Special features are incorporated in videogames for recovery from power failure and software/hardware bugs. Players often insert many quarters at a time for convenience or to keep someone from taking the machine by placing a quarter on the control panel (a socially acceptable way to "cut in"). If a temporary power interruption happens, it is essential that the number of quarters, at least, be preserved in nonvolatile memory or battery-backed static RAM. Similarly, hardware gets confused once in a while and occasionally a player will execute an untested move that hangs up the machine. Many games have a "watchdog" circuit that will automatically jump to memory location zero and restart if not output to at frequent intervals. Thus, if a game gets really locked up or a pointer is lost in a complex data structure, the game can recover without owner/operator intervention. These recovery modes help ensure the physical survival of game machines because unjust loss of a quarter is a frequent excuse for person-machine brutality. An Atari designer says "There are industrial specs, military specs, and Atari specs. Military. specs would never survive Atari play." (Tekla et al., 1982).

In fact, videogames are subjected to the roughest treatment imaginable. Unlike an automated bank teller which confiscates cards if the users get too excited, videogames encourage the thrill part of the interaction. "Body language," the winning edge for any skilled pinball player, has no effect on videogames because gravity is no longer part of the game. However, videogame players do quite stylized dances while firmly anchored to the joystick. Most games can be hoisted by the joystick, thus it is a real design criterion not to give enough of a grip to allow the excited player to pull the game over and forward.

Given that body language does not work and that these machines cannot yet understand what is being said to them, the finger controls are the players' only input mechanism. Most games have buttons and a joystick, although some have a trackball and others (mainly driving games) have a steering wheel and gas pedal. PAC-MAN is simple to play, even for children, because the entire control structure is embodied in one joystick 
with no buttons. DEFENDER is considered much harder to approach initially because its five buttons are conceptually and physically hard to master in coordination with its joystick.

Most joysticks are actually binary "joyswitches," not the analog devices found in computer-assisted design (CAD) workstations. They are simply a pivoted rod which reaches down into the game cabinet a few inches. The rod can be moved to press against switches for up, down, left, and right. There is a heavy-duty plastic insert attached to the switch assembly that, if diamond shaped, allows only one of the four switches to be depressed, and, if a slightly larger square, allows diagonal movement by permitting two adjacent switches to be closed. Interrupt-level software scanning at $60 \mathrm{~Hz}$ usually monitors these switches and accumulates values which are used by coroutines or lower level routines asynchronously.

Generally accepted as the best joystick is the one designed by Dave Nutting as used in GORF and, later, TRON (both the movie and the game, incidentally). It is shaped like a helicopter control, housing a trigger right where the index finger goes, and has room for thumb buttons. The shape helps combat "joystick finger," a temporary indentation caused by the poor knobs on most joysticks. The Nutting handle has lately been modified to send back analog information and is currently featured on a vector game being field tested called EARTHFRIEND. Of course, giving better controls means the designer has to find other ways to beat the player, but such is the essence of the great, evolving, high-stakes metagame of the video arcades.

Buttons, of course, are simple, but they have to be very rugged, yet sensitive and comfortable. Most are about 1 inch in diameter and are convex. Pushing these buttons multiple times per second develops finger muscles that most people would never otherwise use with such intensity. Because future "user-friendly" interfaces to computers will likely borrow heavily from successful videogame controls, perhaps coin-operated game players are indeed training for the future.

Trackballs are 2- to 5-inch billiard-type balls recessed into the control panel. Inside, they ride on two perpendicularly mounted rubber-coated shafts on the end of which are mounted disks with evenly spaced perforations. A light and photocell for each disk reports change information. This optical coupling makes the trackball sufficiently liquidproof to allow its use above the glass in cocktail table games. It is a good device for casual. players; heavy users complain of hand rawness developing. Trackballs do have an interesting mass-in-motion quality deriving from their weight that other controls do not have. A good player can really zip around the screen by quickly accelerating and instantly decelerating the ball with strong hand movements. 
For now, most of the other common computer graphics input devices can be rejected for various reasons. Touch panels are not well suited to specifying motion over time, although they work well in menu-picking applications such as department store information systems. Bit pads (data tablets) are simply too expensive and subject to vandalism, especially the vulnerable styli. Dials have not been too popular because they are onedimensionai, whereas the playing field is two-dimensional (one exception is Atari's TEMPEST, whose rotational control structure is well suited to dial turning). Light pens have the combined problems of tablets and touch panels, although they can be very inexpensively added to raster systems. A mouse control is also not appropriate because a good surface to run the mouse is mandatory and they are easily "lost."

\subsection{Inside the Cabinet}

With the exception of Namco/Atari's POLE POSITION, current coinop (and home) videogames use 8-bit microprocessors. The difference between coin-op machines and home/personal computers far exceeds mere packaging. The latter invariably have keyboards and/or RS232C ports and some sort of rotating secondary storage (disk or tape). Because no case has ever been made for adding character-based input to machines into which people put quarters (except for recording high-scoring players' names, a popular recent addition), keyboards are not considered appropriate to commercial games. Names and initials are put in by joystick and button interaction. Words have little use in videogames; even the text generated by the game or silkscreened on the cabinet is rarely read and is never critical to the play of a game. Typing, of course, is an extremely boring, low-bandwidth communication mechanism completely ill suited to the entertainment industry. Thus, even though adding a bulletproof keyboard can be done for $\$ 10$ or less, keyboards are found only on personal computers and terminals. Of course, educators are nearly completely unwilling to consider a device without a keyboard educationally worthy, which is remarkable because writing is so bandwidth limited.

Disk and tape drives are also inappropriate in the coin-op machine. Tape wears out too quickly and the searching times are geologic compared to ROM. Floppy disks are faster but more fragile, and the seek time is still unacceptably dong. One double-sided quad-density floppy might hold $800 \mathrm{~K}$ bytes and need a $\$ 300$ maintenance-prone drive. On the other hand. $800 \mathrm{~K}$ of ROM is also about $\$ 300$ ( 1983 wholesale prices), needs no expensive drive, is basically indestructible, and is random access with memory-to-memory transfer speeds. Sealed Winchester-type disks have not been used for cost reasons and the fact that they are rather fragile (one 
manufacturer notes in its manual that dropping the drive 2 inches can create a $200 \mathrm{~g}$ force slapping the head against the coated aluminum disk, voiding the warranty). The hope of the industry for rotating memories is the videodisk; this device will be discussed in Section 9.

\subsection{Computer Graphics Display Hardware}

The popularity of videogames derives from the graphics and animation, whose performance is completely derived from the capabilities of the display hardware. The important parameters are the amount of RAM and ROM, the speed and functional power of the special logic driving the display, and the controlling microprocessor. A brief overview of technological game progress over the years will be given in the following discussion, followed by more detailed definitions and descriptions of the several current hardware types. Much of the original work was done in the much more open field of computer graphics. The main contribution of videogames is the mass production and marketing of interaction.

The first visual computer game to gain an acceptance of sorts was SPACEWAR, as played in 1962 on then powerful minicomputers and expensive state of the art refresh-point displays. SPACEWAR, of course, did not have a coin chute. Atari's PONG, acknowledged as the first coinop game (1972), used transistor-transistor logic (TTL) and a few registers to generate video directly and detect paddle "hits." Its chief reliability problem was solved when the coin box was enlarged (it kept overflowing with quarters). Atari's TANK (also done by the PONG crew of Bushnell and Alcorn) was a more evolved TTL game, arriving in 1974.

Shortly thereafter (late 1974/early 1975) the first bit-mapped black and white $(B / W)$ frame buffers appeared in BASEBALL and GUNFIGHT, a system designed by Jeff Frederiksen and Dave Nutting for Bally. These were the first games with animated, recognizable, human-type characters.

BREAKOUT (Atari, 1975) was first a B/W game with colored plastic overlays on the monitor glass, and later in the same year appeared as the first popular color game.

The videogame business really took off in 1978 when Taito (a Japanese company) developed SPACE INVADERS, a B/W game using the Frederiksen/Nutting buffer. Over 200,000 games were sold worldwide, a record that still holds. The big hit of 1979 was Atari's ASTEROIDS, a B/W vector game. Vector later went to 3-D with BATTLEZONE (Atari, 1981) and to shadow-mask 2-D color with TEMPEST (Atari, 1982). The year 1983 brought color and 3-D vector together in Atari/Lucasfilm's STAR WARS and Bally's EARTHFRIEND. 
Meanwhile, the Chicago pinball manufacturer, Williams, was concentrating on exquisite software to control nearly unbelievable numbers of simultaneously moving objects in a 16-color (4 bits/pixel) frame buffer. DEFENDER became the game of choice for expert players in 1980.

Namco, another Japanese company, developed the line buffer for GALAXIAN around 1980. It was also used in PUCK-MAN, renamed PAC-MAN for aesthetic reasons in the English-speaking market. This technology later evolved into the Bally/Midway line buffer system used in TRON. CENTIPEDE, using Atari's object-oriented system, appeared sporting something other than the primary or secondary colors, a nice designer touch. In 1981, GORF and WIZARD OF WOR arrived, both color games based on the custom LSI frame buffer chip set developed for the then canceled Bally HOME ARCADE machine. At about the same time, Nintendo's DONKEY KONG (with apes but no donkeys) raised the stakes in animation and thematic development.

ZAXXON, from Sega, appeared in 1982 and was a visual delight. This object-oriented system with elaborate background tiling allowed considerably more realistic playfields to be incorporated. Large amounts of ROM were used to store patterns cleverly assembled to form a seamless pseudo-3-D moving background. SUPER ZAXXON came out in 1983 to correct some difficulties in ZAXXON; it was a ROM update that was field installable in the existing ZAXXON machines. BABY PAC-MAN, a hybrid video/pinball machine, also appeared in 1983, using the Texas Instruments sprite graphics chip.

Late 1982 also unveiled Namco's POLE POSITION, a driving game manufactured in the United States by Atari. Using two Z-8000 16-bit microprocessors and a good deal of ROM, it is notable for breaking the $\$ 3000$ barrier (it cost $\$ 4200$ ) and for representing processing power comparable to a DEC VAX 11/750. At the same time, Sega and Cinematronics exhibited videodisk-based games and started a truly major scramble among the game industry leaders, much to the delight of the videodisk manufacturers who have not faired well so far in the consumer market.

Hardware designers, then, get to pick from a menu of random scan vector, raster scan frame and line buffers, and object-oriented raster and sprite graphics. Color is now mandatory, at least the primaries, secondaries, and black and white. The richness of the background, object detail, and animation quality are dependent on the amount of ROM in the system. Processing power; RAM availability, and good development systems become the tools for good play design by the inspired game programmer. Far from falling flat, the research in coin-op videogames took off in 1983 and at least promises a good deal of excitement to come. 


\subsubsection{Vector Hardware}

Vector games excel, not suprisingly, in line-oriented graphics and are currently the only way to do full 3-D first-person games. There are two fundamental benefits of random scan systems. First, matrix manipulations on $x, y, z$ endpoint lists result in transformations on the entire lines connecting the endpoints, thus affording great economies of calculation compared to pixel-based systems. 3-D rotation, scaling, translation, and perspective with clipping can be achieved in real time without the aliasing effects found in raster systems. Second, the images automatically erase themselves because they are generated, not stored as pixels in a buffer. (Erasing characters and restoring backgrounds is a major consumer of time with frame buffers.) Of course, vector systems do not have much in the way of backgrounds. In addition, they cannot be synchronized to raster backgrounds. Current vector games are hardware limited to about 500 vectors, not enough to do much realism, thus they are generally applied to outer space themes.

Current coin-op vector machines do not support hidden-line removal or surface generation as found in multimillion dollar flight simulators. Thus, for the time being, vector games give the feeling of moving around in a highly schematized world, an impression that works. This forces concentration on the play of the game, the most important part. A current consumer game, the VECTREX, uses a special built-in monitor to bring vector graphics into the home for under $\$ 200$ ! Both color and red/green stereo versions of the VECTREX were shown at the June, 1983, Consumer Electronics Show in Chicago.

Most vector systems are quite complex, relying on multiple microprocessors, custom bit-slice microcoded processors, and even custom VLSI. it is quite exciting to see a $\$ 3000$ machine do a good deal of the display of a commercial vector device costing 10-20 times as much. The impact of this low-end technology on the vector-oriented CAD industry and its users should be far reaching, indicating the certain appearance in the near future of design work stations costing less than $\$ 10,000$ with the capability of today's $\$ 100,000$ systems.

\subsubsection{Raster Hardware}

Real-time animated raster graphics is important primarily in two application areas similàr in every way but cost: multimillion dollar flight simulators and videogämes. Most commercial raster graphics systems are mainly oriented toward static, high-resolution imagery whose only major real-time effects are the result of color map manipulation. Some commer- 
cial systems allow integer zoom and panning over a data space, but it is difficult for even large computers to move significant parts of a $512 \times$ $512 \times 8$ or $1024 \times 1024 \times 24$-bit image fast enough to animate. Flight simulators use ultraexpensive special hardware. Videogames rely on limiting resolution and/or the line buffer/object system approach.

A frame buffer game such as GORF, with its $320 \times 204 \times 2$-bit screen, needs $16 \mathrm{~K}$ bytes of RAM. Even a relatively slow Z-80 processor can move $80 \mathrm{~K}$ bytes/second, thus about one-quarter of the screen can be updated 20 times/second. Moving over a background can cut this by a factor of three if the background is to be maintained; the procedure is to save the background over which the object will be written, write the object, wait to the next frame update, restore the background (thereby erasing the object), and go on. Thus, three writes are required for one object move. Case-specific optimizations can improve the situation, of course, and it must be remembered that these objects are small to start with. Dozens of 64 -byte patterns $(16 \times 16 \times 2$-bit images, for example) can be moved in real time.

Great care is taken to synchronize with the television beam scan so that the save/write/restore cycle does not collide with the beam, creating an ugly flutter and/or viewing of partially moved objects. Objects are updated when the beam is far enough away to avoid beam collision. A helpful interrupt is included with most systems and can be triggered by horizontal retrace to indicate beam position. The important objects are thus updated at interrupt level to assure quality imagery.

The Williams buffer used by DEFENDER, STARGATE, JOUST, BUBBLES, and SINISTAR has 4 bits/pixel yielding 16 colors on a 32Kbyte screen. Eugene Jarvis and Larry DeMar are highly praised for the extremely clever software algorithms that make these games move very
fast.

Frame buffers represent the most flexible technology from the raster image point of view. Any size image of any complexity within the confines of the resolution can be built and held at no additional cost, although large subimages will not animate fast enough, in general. Lines may al:so be drawn, although staircasing is a problem unless used for effect. A keying (or overlaying) circuit can allow a background to appear wherever the foreground objects have zeroed pixels, thus making an update a once-only write situation, at the cost of doubling the memory, of course. Erasing can be done by writing characters stored with a frame of zero pixels all around or at least on the sidess) opposite to the direction(s) of movement. The frame has to be as wide in pixels as the largest jump the object will take. Each successive write erases the old image and puts down the new. If animation is wanted, the images are cycled. 
Because memory was much more expensive a few years ago, other ways of keying small objects over backgrounds were developed: the sprite system, the object-oriented system, and the line buffer.

Sprites are hardware image subroutines and were first used in the Texas Instruments graphics chip. As the hardware scans the background, it checks if any of the sprites are set to be at that location. If so, the appropriate horizontal line portion of the sprite is substituted; when finished, the background resumes. The background can be a full buffer or some sort of generated pattern like a checkerboard or stripes. The number of sprites is fixed at four per line by the chip.

Object systems use fixed-size characters and are an extension of the technology of the standard alphanumeric terminal [which, remember, uses 1920 bytes of RAM to specify the equivalent of a $480 \times 240 \times 1$ $(14,400$-byte) buffer]. Just as the alphanumeric terminal is constrained to displaying only the characters it has stored, the number of defined objects can be quite limiting in object systems. Spirals, for example, are rarely seen because many objects would be used in defining the necessary increasing arcs in advance, or too much processing power would be needed to define them on the fly. Objects can be moved quite rapidly because only pointers have to be changed (in alphanumeric terminals, the ASCII code is precisely a pointer to an image lookup table, of course). The coin-op hardware used by Atari's CENTIPEDE is a good example of an objectoriented implementation.

Line buffers are conceptually like frame buffers except that each line of the image has to be generated or composed of pointers just in time for the video scan-out. Background or objects of any size can be assembled, limited only by what the hardware buffer loader can accomplish in horizontal retrace (11 $\mu \mathrm{sec}$, not much) or, in the case of double-buffered line buffers, the whole horizontal line time $(63.5 \mu \mathrm{sec})$. The microprocessor can, of course, use the rest of the available time including vertical retrace to set up pointers and lists.

The resolution of line buffer systems can be quite high because one can afford fancy, bipolar high-speed RAMs for the one or two lines worth of memory needed. Keying is done automatically by the buffer loading logic. Objects of any size can be considered and colors can be quite varied because the number of bits/pixel is more bandwidth limited than cost . limited.

\subsubsection{RAM and ROM}

To large-volume customers such as videogame manufacturers, RAM costs about $\$ 700$ per megabyte and ROM is half that price (in June, 1983). 
ROM is used for storing programs and image patterns. Older games such as PAC-MAN had 16K of ROM for program and $8 \mathrm{~K}$ for images. Newer games (ZAXXON) have much more image ROM than program ROM. It is much faster to improve the look of a game by increasing the image complexity than it is to write, for example, $64 \mathrm{~K}$ bytes of useful program strategy code, especially in the assembly languages running on 8-bit microprocessors.

Therefore, whereas the game artist primarily craves ROM, the programmer wants both ROM and RAM. Game programmers with a few computer science courses realize that data structures are the basis of any "intelligent" management of sophisticated tasks. Early games had very little RAM, often as little as 128 bytes for a stack and a few flags and score values. Now, programmers use RAM to build tables of information to keep track of what the player is doing. Thus, RAM is the key to variable strategy and the means by which games will approach artificial intelligence.

The videodisk is, of course, ROM. The current prototype games use the ROM only for storing pretty pictures in analog video format. Ralph Baer, the holder of many video and computer patents, advocates storing data as well (Bloom, 1983). The videodisk is a ROM more or less equivalent to $55,00016 \mathrm{~K}$-byte blocks (ignoring dropout), a formidable amount of storage. As a medium, it has the advantage that it is hard to copy, thereby minimizing piracy, yet inexpensive to fabricate-an excellent distribution medium.

\subsection{6-Bit Microprocessors}

The development of $\$ 10$ microprocessor chips fully in the league of PDP-11/45s is truly encouraging. A group at Osaka University in Japan has linked $64 \mathrm{Z}-8000$ s in parallel and claims it to be the world's most powerful computer. Videogames will not be far behind in exploring massive parallelism. Still, management must be convinced of the need for developing software to make the power really usable rather than just theoretically available.

In the meantime, just having multiply-and-divide instructions and ways to go indirect in one instruction make possible more sophisticated realtime algorithms. The, 10 -fold increase in speed of the 16-bit micros allows high-level languages to be seriously considered.

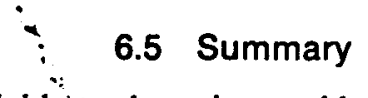

The hardware available to the coin-op videogame designer is no longer simple. Bit-slice logic, large programmed-array logic chips, and custom 
VLSI, all becoming easier and easier for even software people to understand, are eliminating processing bottlenecks. The hardware industry is pushing personal interactive technology faster and harder compared to any other industry. Interestingly enough, the process is at least temporarily fueled by the obsolescence of year-old games which have to be discarded, the lack of requirement for upward compatibility, and the demands of an increasingly sophisticated game-playing public. It is amazing technology available at the price of an already rusting used car.

\section{Videogame Software}

Game programmers occasionally get to affect hardware design, but most often they do not. Also, they rarely have much of a say in specifying the tools they work with; the development systems are generally primitive. Game artists complain that their workstations are created by people who do not use them. Add to these frustrations the time pressure and what game designer Tim Skelly calls the "hit syndrome" (anything that is not an immediate hit is pulled by management) (Tesser, 1982). It is easy to see why game programmers are a rare breed.

These programmers certainly see themselves as software stars, akin to science fiction writers and rock groups. Some are now engaging agents to negotiate royalties. Although there is talk of designer/artist/programmer teams, the creative effort behind games so far has been by those who program. The basic tenets of videogame software are the subject of the following discussions.

\subsection{Game Design}

The fundamental rule of game design has emerged as "play first, graphics second, sound third." "Play" is the hard-to-define interaction between objects and the requisite timing considerations. Based on an extensive interview with Jan Hendricks (Hendricks, 1983), an independent game designer/artist who has worked on WIZARD OF WOR (Bally) and JOUST (Williams), these definitions and concepts emerged. Note that all coin-operated games (except quiz games) currently have at least one type of enemy whoşe main job is to cause the game to end. Enemyless games are thus not subject to this analysis.

There are four types of enemies, according to Jan Hendricks: main enemies. metamor̀phosing enemies, intelligent enemies, and wave enders. Enemies divide the field of play and impose restrictions on the player, which include time (cannot play too long), space (cannot remain in one place very long), and essentially everything else in the game strategy. 
Games are usually structured in "waves." A wave is a repopulation of the playing field with a rack of new enemies (as in SPACE INVADERS), new dots (PAC-MAN), or a different background, maze, or scene. Each wave gets more and more difficult and challenging, often employing new strategies, faster speeds, and meaner enemies. The first-wave enemies are the easiest to understand; they are called "main enemies."

There are two types of main enemies, tracking and nontracking. The latter come in both animate and inanimate varieties. Walls whose touch is death, as found in driving games, for example, are inanimate main enemies, as are the more imaginative stationary electrodes in ROBOTRON 2084. Nontracking animate enemies wander around but do not follow and do not shoot at the player-controlled object, although avoiding them is advised. Main tracking enemies are slow but sure, and there are typically swarms of them. Their purpose is to keep the player moving (SPACE INVADERS is composed entirely of this type enemy).

In early games such as SPACE INVADERS and PAC-MAN, time limits were enforced by simply speeding up the game with each new wave until the main enemies were coming so fast that they could not be avoided. To keep good players coming back, the idea of being able to win has to be maintained. Players must believe it is their (minor) fault that they got trapped/shot and that they can do better with the next quarter. Chris Crawford from Atari says.

In every game the players are expected to fail often. What trips up the players? If they believe their failure is caused by some flaw in the game or its controls, players become frustrated and angry with what they rightly judge to be an unfair and unwinnable situation. If players perceive their failure to be a result of their own limitations and decide that winning the game requires superhuman performance, they reject the game as unfair and unwinnable. But if players perceive failures to be attributable to correctable errors on their own part, then they believe the game to be winnable and play on in an effort to master the game. [Crawford, 1982].

Thus the development of cleverer enemies was mandated.

The second type of enemies, metamorphosing enemies, are those whose danger increases over time. The player must eliniinate these while still in "cocoon" stage, when' picking them off is easy, otherwise they change into deadly enemies usually with some sort of homing capability. In DEFENDER, lander's turn into dangerous mutants; in JOUST, eggs hatch into riders attracted to live targets.

Intelligent enemies are the third type. Because chess-type strategies can hardly be expected in real time, these enemies' intelligence is based on knowing the location of the player and how to attack in various ways. GALAXIANS was considered an improvement on SPACE INVADERS 
because the aliens could track fairly well. In newer games, the intelligent enemies gang up on the player. In JOUST, they come from above and below simultaneously. The player has to see the situation coming before it is too late and take evasive action fast.

Finally, wave enders are cataclysmic events or very nasty creatures that appear when a player survives a wave for a prolonged period of time, racking up many points. Advanced players can avoid the other types of enemies and might spend too much time picking off minor targets, a boring way to beat the game. Wave enders thus appear after a certain time in a wave and the advanced player gets out fast or loses.

Games that do not have wave enders can sometimes be played forever. Atari's BATTLEZONE strategy could be defeated by continuously backing up the player's tank. This otherwise fine game was therefore not appreciated by owner/operators once this problem was discovered and communicated by players.

As an example of the continuing development of these concepts, Atari's XEVIOUS (developed by Namco) has 14 different sky enemies and 11 different ground targets, all of which shoot back. Read the ad copy:

You are Earth's last hope. They're counting on your skill to wipe out waves of attacking enemy aircraft and endless streams of hostile land bases ... BACULA resistor shields, ZOSHI Death squads, GROBDA tanks, the ANDOR GENESIS mother ship ... all trying to blast you out of the sky. Are you hot enough? You'll have to be sharp. Because as you get better the Xevious forces get more devious! More dangerous! [Atari, 1983].

\subsection{The Player}

The player has to be the most scrutinized character in the game. In third-person games, the player is embodied in a rocket ship, PAC-MAN, or other appropriate icon. This embodiment must be under the player's lag-free control, thus its update must be done under high priority, unless the effect of introducing delay is part of the game. The edge must go to the player; if shots are fired simultaneously, the player should get the points.

The game must be designed to have human reflexes work for the player. Control difficulty excludes all but the very good players, if not everyone. Poorly designed control structures are dismissed as "stupid." A good example of usage.is the steering wheel in Atari's POLE POSITION which aims the player straight ahead whenever the wheel is held stationary, not just when it is returned to " 12 o'clock high," as is the case when driving a real car. Tests showed that players could react faster with this modification. Counterexamples include the five buttons in Williams' DEFENDER 
which are hard to master, the trigger in Bally's TRON which is used for speed instead of firing, and the upside-down joystick in Sega's ZAXXON for which back means up and forward means down (which might work if ZAXXON were a first-person game).

One of the unrewarding aspects for the good player is having to work through the first few waves in order to get to the challenging parts. Namco/Bally's BOSCONIAN allows the player to continue in the current wave if extra quarters are in the machine or one is added within 10 seconds. In addition, many games allow the owner/operator to set a difficulty level on an internal dip switch, based on sensitivity to the expertise of the clientele and/or the desired profit at the location. Another idea is to allow a player to select a wave as a starting point and award the points normally accumulated up to that wave if the player survives.

In retrospect, all these refinements seem simple enough. One wonders why each small step requires tens of thousands of machines as sacrifice.

\subsection{Strategy}

As mentioned before, the microprocessors used in videogames do not have much time for real-time artificial intelligence. Fortunately, neither does the player (and this is one of the criticisms of educators). Is "strategy" too strong a term for game logic/player logic? The "how-to" books counsel memorization of the maze patterns they publish, not exactly what can be called "strategy." The player is advised, for example, in Williams' ROBOTRON 2084, to try to get to a corner; in Bally's WIZARD OF WOR, to hide; and in DEFENDER, to collect his men. The early game SPACE INVADERS, very tedious to watch as a nonplayer, at least provides the opportunity to pick off the rack of aliens in different patterns (edges, alternate rows, the bottom row first, and so on) in order to better the chances of getting to the next wave. In many games, strategy is really just idiosyncrasy, but consumers seem to love idiosyncrasies in products and gain self-image through their mastery.

\subsection{Animation}

Animation techniques are rather dependent on the hardware. They can be divided into two types: vector and raster. Vector graphics are drawn random scan and are easily geometrically transformed as wire-frame objects in real time. Raster. images can be moved only in $x$ and $y$ directions and possibly rotated by $90^{\circ}$; animation is done as in cartoons by flipping different images at least 12 times a second. Neither system can generate shaded surfaces of significant complexity in real time like the high-end 
commercial buffers and flight simulators, although it is possible to flip through stored images of any complexity if the ROM space is available to hold them. Whereas the animation techniques for raster and vector differ considerably, the control of either type of image over time is a problem held in common.

\subsubsection{Vector Animation}

Vector images are manipulated by matrix mathematics applied to endpoints stored in vector lists. The hardware/firmware of the display perform the transformations and draw the lines that make up the images. The logic part of the display is generically called a "geometry engine" (Clark, 1982 ). These new chip-based systems are similar to the $\$ 50,000$ vector display devices available for the last 15 years in the commercial market, with the obvious but acceptable difference that they draw far fewer vectors flicker free.

Images composed of vectors are, of course, quite abstract. "Popeye," for instance, would be an unlikely candidate for a vector game. On the other hand. consider "aliens." Suppose they are constructed of bright, colored wires and are capable of turning themselves into something else via linear interpolation for strategic or entertaining purposes. The application of mathematical formulas to the transformations possible with vector graphics yields an inexhaustible wealth of pleasing and exciting effects, whereas. in raster graphics, the use of much in the way of mathematical transformations in real time is not possible. Microprocessors simply cannot manipulate many data. In vector graphics, only the endpoints are changed by the processor. The lines are generated by special-purpose logic. In raster graphics, all the pixels in the line must be recomputed each time and plotted, often a 100:1 handicap.

The most attractive part of vector graphics now is the ability to render schematized 3-D scenes that the player controls first person, something raster graphics systems (as in POLE POSITION) are just starting to ap-
proximate.

\subsubsection{Raster Animation}

The animation of frame buffer raster images requires considerable memory movement. Line buffer and object-oriented graphics need only change pointers to effect changes. Tim Skelly, one of the few designers who are both artist and programmer, says

\footnotetext{
On a raster system, every dot-or pixel-on the screen has a certain number of bits in the machine's memory describing it. The artist can literally work each individual dot
} 
on the monitor screen-color it, change its color, hue, intensity-until he gets just exactly what he wants up there. Now, if you want to animate what you've put on the screen, it's really a lot like animating a cartoon. You 'draw' a series of frames for each of the objects and each of the moves you want it to make-walking, turning, shooting, whatever-and then you build cycles of movement into the program for the various gameplay contingencies. [Mecoy, 1982].

The quality of the animated image is dependent on the number of images in the cycle and the resolution of each image in terms of $x, y$, and color. More images in higher resolution and more color require more ROM for storage, therefore the drop in ROM prices clearly allows better animation in a $\$ 2800$ machine. Better looking animations also entice holders of properties such as Popeye and movies such as Star Wars to license their characters.

Animated objects do not have to be large to have character. JOUST is a game highly praised for its animated ostriches and buzzards, the largest of which are $24 \times 16$ pixels (an area about $0.5 \%$ of the screen). Size is critically important. Very small or very rapidly moving characters are not worth animating because effects are lost in the resolution or the motion blur. Larger objects $(16 \times 16$ pixels, for example) start to look quite attractive when animated using four or more different images in a cycle.

Much larger images ( $64 \times 64$ or greater), however, begin to pose problems which limit their usability. First, they tend to dominate the playfield, making it look smaller. Second, large objects take too long to write. A $64 \times 64 \times 4$-bit/pixel image uses 1024 bytes, about one-quarter of what you can flip 20 times/second going full speed. Third, as an object gets larger and moves slower, it needs far more images in the cycle for the animation to look good. Thus, ROM needs increase by a factor between the square and cube of the size of the object.

Stationary objects such as backgrounds should be high resolution, a problem for game systems because a $512 \times 512 \times 8$-bit image requires a 256K-byte frame buffer and similar ROM storage for each different screen. Some systems, those used in ZAXXON, for example, allow "tiling" of backgrounds which is essentially the generation of backgrounds by manipulating lists of pointers into image elements much as standard alphanumeric terminals generate text screens. Rather varied backgrounds can be specified this way. Characters can also be made up of tiles, allowing partial updates for, say, the mouth and eyes, without changing the rest of the object.

Research in computer graphics has indicated that fully antialiased $256 \times 256$ images are quite attractive. Antialiasing requires at least 8 bits/ pixel (thus a $64 \mathrm{~K}$-byte buffer for $256 \times 256$ ) and significant preprocessing of the images stored in ROM (no problem there). Most programmers 
would rather have more bits/pixel than greater spatial resolution, but they are often overruled by marketing.

Another benefit of increasing the number of bits/pixel is the ability to treat the buffer as independent image planes. When combined with a color table lookup mechanism (color map), considerable in-place animation can take place simply by changing the values in the table (Shoup, 1979; Foley and Van Dam, 1982). If the images do not overlap, $2^{* *} n-1$ one-color images can be specified in a cycle with $n$ bits/pixel. Usually, however, overlapping is common, thus only a part of the color map is allocated to cycling, a good way to simulate fire or running water, for example.

Another animation trick using frame buffers is exclusive-or (XOR) writing of images. The first XOR write puts the image down, the second one will erase it. Even if the background is not all zeros, the erase is complete and the background is restored. If the color map is used cleverly, the new colors created by writing over a nonzero background can be mapped into old ones, thereby establishing whether the object passes in front of or behind other objects or the background. Of course, to make this efficient, the hardware should have XOR capability in pattern transfer mode, as is the case in the chip set of WIZARD OF WOR and GORF.

\subsubsection{Control of Images over Time}

Videogames such as PAC-MAN and SPACE INVADERS have relatively few motions to accomplish and only a small number of possible collisions to detect. A loop running during vertical retrace, testing a hundred or so events, can be easily imagined. Keeping missile projections horizontal or vertical reduces by half the testing complexity. Keeping enemies sorted by $\mathrm{x}$ or $\mathrm{y}$ can dramatically cut software collision-detection time.

Many systems have hardware collision detection built in. A bit is set whenever an object writes over nonzero memory. The software then checks exhaustively to find out what was hit. More sophisticated hardware generates an interrupt on collision, thus the software needs only to keep track of what is being written at any given time, although it still has to search for what was written over.

Interrupt-lęvel processing is extensively used in videogames. Interrupts tell when to update a screen to avoid beam collision (scanning of the part of the screen that is changing). Sound, melodies in particular, when occurring in conjưnction with animations, is accomplished by sending out parameters to a sound chip at interrupt level to guarantee the even timing of notes.

Controlling the motion of many objects at once is done by building tables containing a pointer to each object, the current position, fractional 
increments or the goal positions for $\mathrm{x}$ and/or $\mathrm{y}$ motion, and the time (in sixtieths) left to get to the goal. At every update, moving objects are rewritten and the table entries updated. In the fractional increment case, the formula is

$$
\begin{aligned}
\text { increment } & =(\text { goal }- \text { original position }) / \text { sixtieths } \\
\text { new position } & =\text { current position }+ \text { increment }
\end{aligned}
$$

The increment has to be kept as an integer plus fraction so that errors do not unduly accumulate. The new position is calculated every sixtieth second by a single multiprecision addition for $x$ and $y$. Another simple but powerful formula is

$$
\begin{aligned}
\text { increment } & =(\text { goal }- \text { current position }) / \text { sixtieths left } \\
\text { new position } & =\text { current position }+ \text { increment }
\end{aligned}
$$

where both lines are evaluated every sixtieth of a second. Although this method requires a divide each time, it does allow the goal or the time left to be altered anytime, permitting nonlinear tracking effects that can be quite interesting.

More complex motions can be accomplished by table lookup. A table of sines can be used for weaving, corkscrew, or circular/elliptical motions. People, being good at pattern recognition and anticipation, find it enjoyable to track complex periodic motions. Namco/Bally's GALAXIAN and GALAGA games are good examples of complex swooping motion. Chris Crawford describes his use of systems of coupled differential equations (Crawford, 1982), indicating that at least one game designer uses classical numerical analysis in animation schemes.

It is necessary to mention one further point about animations. Elaborate animations are time expensive, detracting from strategy-computing time. Minor events such as the death of a lesser enemy should be unspectacular and should not slow down the player. Player death, however, is a good time for pyrotechnics because the player has need for at least a bit of relaxation to enjoy the catharsis before the next onslaught. The other gooc place to show off is during the attract mode of operation when i people are witching, not playing.

\subsection{Language and Development Systems}

By now, it should be clear that any amount of human effort is justifiable in producing a winning game as long as the development does not take very long. Because a'good game run, say 20,000 games, will consume maybe $\$ 18$ million in hardware, an extra $1-2$ person-years devoted to software will not be a problem, especially if a RAM or ROM chip can be eliminated. Because coin-op games are designed to run on only one hardware system for a short period of time, upward compatibility and portabil- 
ity, primary design criteria in the rest of the software industry, are not important at all.

Getting the game done quickly is critical. It is not possible to speed the process, however, by adding more programmers. Higher level language of some sort is obviously desirable. Yet, there are no languages optimized for building the kind of real-time task handlers and data structures required by interactive graphics. Higher level languages routinely discourage flexible data-type mixing that is very important in real-time trickery. (The "C" language overcomes some of these difficulties on 16-bit machines.) At best, the approach thus far has been to develop a game operating system with enough subroutines and effects programmed in to make the game programmer's job much quicker to do. A sufficiently rich set of assembler macros can go a long way toward achieving the beneficial effects of higher level language without the run-time overhead.

One middle-level language, popular among game developers, especially those whose job it is to work with untested hardware, is FORTH. Game "tweaking" requires excellent real-time tracing and debugging facilities, a feature of FORTH. Assembler routines can be easily added and the probability of once again seeing a machine running FORTH-type code directly is very high.

It is likely, however, that assembler will be used extensively far into the future. Game programmers tend to get brand-new state of the art microprocessors, custom chips, bit-slice logic, and, in general, computing equipment that barely has even a working linking loader. Furthermore, machines such as logic state analyzers, which are critical for solving probiems involving hardware and software clashes, work only in assembly/machine language.

As the 16-bit micros catch on, some design tasks will be done in higher level language. However, a problem already exists with what Eugene Jarvis calls "generic videogames" (Jarvis, 1982). People can easily perceive the overall structure and effects repertoire of a game. Encountering these again does not make for excitement. For example, Sega's CONGO BONGO has apes, waterfalls, and jungle scenes, yet it is tediously similar to the outer space ZAXXON game whose system it shares. It is an open question whether high-level software constructs will not also be perceivable and, therefore, not new or exciting when shared among several games.

\subsection{Dèvelopment Systems and Artist Work Stations}

Videogames are usually developed on a microprocessor computer system having disk drives, a terminal, a printer, and, most important, an in- 
circuit emulator (ICE) capability. The ICE allows the computer system's microprocessor, which is the same as the game's, and some of its RAM to usurp the corresponding parts of the videogame hardware. A cable connects the computer system to the game box and either replaces the game's microprocessor by plugging into its socket or attaches to the bus. Thus the programmer can debug programs in RAM instead of continually remaking erasable programmable ROMs (EPROMS), a big time saver.

Coin-op game development systems are generally composed of a pile of shop-made plywood boxes with clip-leaded interconnecting wires and cables going everywhere. Moving one of these systems even down the hall takes a major effort. These systems never reach the level of stabilization of hardware or software that programmers routinely expect from commercial or consumer computers because every one is, in effect, a prototype. The time pressure involved in game creation usually means that the top programmers do games, not systems, and that no one gets to take off 2 or 3 years to develop a good language. [Of course, no one really knows how to do a language/system that everyone else will want to do their languages and systems in, and trying to fully develop one is the most seductive trap a programmer can fall into; see Chapter 5 in Weizenbaum (1976).] In addition, royalties, if any, go to game implementers, not language designers. Given these obstacles to reasoned effort, the primitive state of the tools in the videogame business is understandable.

Commercially available systems are rather hard to integrate into the game development process. A standard time-sharing VAX, for example, cannot attend very well to a commercially available frame buffer with the speeds necessary to simulate a videogame. The tricks needed in videogame hardware are not found on commercial buffers, and interfacing Jideogame hardware to a VAX, for example, is nearly impossible. It is possible to imagine a single-user CRAY running a very complex simulateanything game system, but impossible to consider seriously implementing it for cost reasons.

If the programmer's situation seems is appropriate for being a key factor in a $\$ 10$ billion industry, the artist's is worse. Artists, who are generally paid much less than programmers, have to cope with tools which they cannot modify and which are programmed by people who do not use them. Artists, whose animations define the look of the game, use equipment so primitive that design on graph paper is still prevalent in the industry. Although artists now get to see their raster images cycle in place, no artist work station is yet rumored to allow animations to be modified interactively while integrated with game logic.

Some say that artists do not know what is possible, therefore they cannot ask for it. A new breed of artist/programmer is emerging from 
places such as the Massachusetts Institute of Technology and several schools in Chicago. These people are taking computer courses and are learning what they want and how to develop it. They are not content with menu selection of engineer-conceived possibilities and are willing to become good programmers to do their art.

One emerging trend is to bring Hollywood-type movie directors and toy designers into the "team." Because the trend is toward "interactive movies" and their toy spin-offs, this is an understandable conceptual leap for management to take. The programmers and artists are not pleased in general; they see videogames as an entirely new medium and would rather have a basketball coach around than a movie director (Murphy, 1983). The emphasis is on real-time interaction and strategy, neither of which is the essence of movies or most toys. Furthermore, literary quality is expected of movies, being an outgrowth of theater and being reviewed by people who write for a living. No one expects great literature or even meaningful dialog in a videogame.

A dramatically new game chassis is generally the work of one of the handful of people who are simultaneously gifted in hardware, software, and visual design. We are accustomed to great mathematicians being occasionally also competent musicians or artists; the same is often true of great programmers and engineers. Part of the reason for the success of Japanese videogames in the world market is the historical concern for the visually aesthetic in Japan's culture. Most of the successful coin-op games in use in the United States today are designed by Japanese, despite the fact that no other form of Japanese software (music, movies, literature, art, programming languages, operating systems, application programs, etc.) has had anything but trivial market penetration here.

\subsection{Sound In Videogames}

Sound has, so far, been treated as the least important part of a coinoperated game, but it can often be used to advantage. Sound people cannot expect a reasonable environment for enjoying their work; either the machine is in a typically very noisy arcade, or the sound is turned down so as not to disturb nonplaying customers in the location.

SPACE INVADERS, a good example, has a dull thump accompanying each shift of the rack of aliens. It sounds somewhat similar to a heartbeat. As the player eliminates the aliens, the rack can move faster because fewer aliens have to be updated, and the sound speeds up. By the time the last alien is destroyed, the beating has worked up to a frenzy, an exciting feature of the game.

In GORF, the sounds of enemy lasers occur before the player is 
reached, thus, in essence, a warning is issued. Stereo sound could be used to help the player locate impending dangers.

Voice, even the mechanical VOTRAX type, is effective. Being insulted or grudgingly complimented by a machine opponent definitely adds to the play.

\subsection{Summary}

Videogame programmers appear to be maturing as a breed. The wild days of the boom are past and videogame design has become a serious endeavor. These people deserve better tools and it is encouraging to hear of significant funding for development systems and artist work stations.

\section{Legal Issues}

The following discussion is meant to give the reader an idea of the impact videogames have had on judges, lawyers, and the legal system in general. Although the importance of an IBM-Hitachi altercation is easily understandable, it is rather bizarre to see a row of coin-op videogames and a row of allegedly infringing copies facing each other in federal district court. It is more amazing to note that some manufacturers spend more on legal services than on research. The comments in this section are based on observations made while serving as an expert witness and should not be interpreted as legal advice.

The first problem encountered by the manufacturers and owner/operators comes directly out of the pinball heritage. Legitimate and hysterical interests claim various deleterious effects of videogames and try to ban them from certain locations and/or age-groups. The manufacturers claim constitutional guarantees to play videogames, which the courts, by and large, are granting. Each locality tries a different twist to outsmart the last court ruling, and the game goes on. Federal district courts have jurisdiction only over th sir own areas, thus the same case may have to be tried in several locations.

One indicator of parental attitudes is the difference between advertising directed at them and their children. In the glossy brochure describing Atari Computer Camps, 22 camper activities are listed, computer programming being the first. Videogames are not mentioned, although chess and checkers are listed. The pitch aimed at children concentrates on the pleasure of eliminating alien attackers, on the other hand.

Outside the United States the legal situation is entirely different. The Phillipines and Indonesia have outlawed videogames entirely. Dr. Martin 
Khor, of the Consumers' Association of Penang (Malaysia), says "Videogames are destroying our traditional games and children are no longer interested in, say, flying kites or top spinning." (Japan Times, 1982). The situation is different economically, too. Copyright protection for circuit boards is nearly nonexistent, thus "knock-off" games completely dominate the market in many foreign countries, including those in western Europe.

Another topic for litigation appeared when the "how-to" books on maze games appeared. A manufacturer sued on the grounds that income was lost because players, after having read the book, could stay on the machine for much longer. (Actually, being able to beat a machine is no fun, therefore in some ways the argument had merit. Movie reviews do not generally reveal the ending, after all.) Freedom of the press won this case, but the "how-to" books directly helped create the market for "speedup" games.

An expert programmer can follow enough of a disassembled listing of a ROM to make a few patches and trivially change the nature and look of a game. Recently, this ability has been used to release versions of popular games with increased speed and features. These changes invalidated much of the "how-to" book "wisdom." The games became harder to play, some would say more challenging, but many players expected the original games' behavior and were upset. The manufacturer sued the speedup kit vendors on the basis of violation of copyright, both on the basis that the program itself was registered (and it was clearly a case of modifying a copy) and that the audiovisual work was also registered, as are movies and Disney characters. The copyright law specifically protects authors from unauthorized mutilations of their works.

The defendants countered that videogames are not copyrightable because each time a game is played it becomes a new and distinct audiovisual work. The player, they argued, is coauthor of the new audiovisual work. Furthermore, games have random sequences, they claimed. The Seventh District Court did not agree. Games, in fact, have pseudo-random-number generators (unlike slot machines which derive the seed from player response time), and thus the same sequence is played each time, given the same input's. (Actually, this is why the "how-to" maze books are useful in the first place.)

A major confusion resulted from a decision that hexadecimal code in a ROM was not copyrightable because the judge could not read it. The law allows copyrighted material to be read with the aid of a machine. Even the order of playback is not an issue; a movie can be copied backward and still be in violation. Recently, a court in Chicago decided that ROMs were copies of programs which could be protected. 
A larger issue surfaced in the PAC-MAN v. K. C. MUNCHKIN case. Here, the code ran on a different processor, thus no copying of the program was involved. K. C. MUNCHKIN had the "look" of PAC-MAN, and a lower court did not find that enough reason for violation. A court of appeals decided otherwise and granted an injunction. Recently, the Supreme Court refused to take the case, and it has now returned to the lower court for award of damages. PAC-MAN may be low resolution, but he is protected. Of course, now that PAC-MAN has been reverse engineered into a cartoon character, complete with a personality, emotions, a family, and even a dog named CHOMP CHOMP, and everything from a PACMAN telephone to wall-to-wall carpeting and candy can be purchased, the issues get hotter. Not bad for a "grapefruit," as his cartoon voice, Marty Ingels, called him (Adamo, 1983a).

Note that these points of litigation are software related, in a broad sense. Hardware protection is given by Patent Law, and the courts have been busy trying cases of infringement since PONG days. One company has a patent on using simulated paddles in videogames, another on frame buffers for games, and so on. Because a large percentage of granted patents are later undone by courts, the videogame industry promises to be as fertile a ground for litigation as the petrochemical industry.

Videogame copyright and patent decisions have a great impact on computer systems and software in general. The legal system is writing new law in this area. Clear rulings will help overall with the larger strategy of advancing technology, at least in the United States. Such litigation is an order of magnitude more difficult in foreign countries and far more costly. Fortunately, the International Trade Commission (ITC) has been effective in seizing violating hardware upon entry to the United
States.

The protection of property is essential to the private funding of research and development in this field. It should remain an interesting subject to follow for years to come.

The following list includes citations for videogame copyright and patent infringement cases (note that Midway Mfg. is part of Bally Corp.).

1. Midway Mfg. Co. v. Artic International, Inc., Seventh Circuit, 704 F.2d 1009; 1983.

2. Williams Electronic, Inc. v. Artic International, Inc., Third Circuit, 685 F.2d; 1982.

3. Atari, Inc. et al. y. North American Phillips Consumer Electronics Corp. et al., Seventh Circuit, 672 F.2d 607; 1982.

4. Stern Electronics, Inc. v. Harold Kaufman d/b/a Bay Coin et al., Second Circuit, 669 F.2d 852; 1982. 
5. Midway Mfg. Co. v. Omni Video Games, Inc. et al., First Circuit, 668 F.2d 70; 1981.

6. Magnavox Co. et all., Appeal of: Universal Research Laboratories, Inc., Seventh Circuit, 627 F.2d 803; 1980.

7. Williams Electronics, Inc. v. Bally Mfg. Corp., Northern District of Illinois Eastern Division, Slip Opinion; April 20, 1983.

8. Nintendo of America, Inc. v. Elcon Industries, lnc. et al., Eastern Division of Southern Michigan, Slip Opinion; October 4, 1982.

9. Midway Mfg. Co. v. Bandai-America, Inc. et al., District of New Jersey, 546 F. Supp. 125; 1982.

10. United States of America v. Michael Stevens et al., Northern District of Illinois Eastern Division, 543 F. Supp. 929; 1982.

11. Publications International, Ltd. et al. v. Bally Mfg. Corp. et al., Northern District of Illinois Eastern Division, 215 U.S.P.Q. 861; 1982.

12. Nintendo of America, Inc. v. Bay Coin Distributors, Inc., Eastern District of New York, CCH Copyright Law Reports, P25,409; 1982.

13. Midway Mfg. Co. v. Artic International, Inc., Northern District of Illinois Eastern Division, 547 F. Supp. 999; 1982.

14. Atari, Inc. et al. v. North American Phillips Consumer Electronics Corp. et al., Northern District of Illinois Eastern Division, CCH Copyright Law Reports, P25,363; 1981.

15. Atari, Inc. v. Amusement World, Inc. et al., District of Maryland, 547 F. Supp. 222; 1981.

16. Total Video, Inc. v. Benson Miller et al., Southern District of New York, 526 F. Supp. 561; 1981.

17. Midway Mfg. Co. v. Dale Dirkschneider et al., District of Nebraska, 215 U.S.P.Q. 336; 1981.

18. Midway Mfg. Co. v. Dale Dirkschneider et al., District of Nebraska, 543 F. Supp. 466; 1981.

19. Williams Electronics, Inc. v. Artic International, Inc. et al., District of New Jersey, CCH Copyright Law Reports, P25,503; 1981.

20. Midway Mfg. Co. v. Artic International, Inc., Northern District of Illinois, CCH Copyright Law Reports, P25,337; 1981.

21. Stern Electronics, Inc. v. Harold Kaufman et al., Eastern District of New York, 523 F. Supp. 635; 1981.

\section{Future Developments}

When pondering this force, the videogame entity, financially equivalent to commercial television, a feeling of zooming predominates. The follow- 
ing discussion briefly outlines some of the more technologically feasible ideas likely to appear in the hardware and software of upcoming games.

Better graphics is a sure thing. Characters are likely to get wounded and die slower than presently. More control over terrains in 3-D and effects of rotation and scaling comparable to those available in the Quantel and Ampex high-end special-effects generators for television production will soon become part of games. The 16- and 32-bit micros running at $25 \mathrm{MHz}$ in conjunction with custom chips and semicustoms will give programmers plenty of challenge. Strategies will rely more and more on artificial intelligence research techniques. Perhaps games will come along for which the player even gets to construct part of the fantasy world of the game.

The industry is watching new developments closely. The quiz game, PROFESSOR PAC-MAN, will have to make its own market. Several independents have designed new-concept games which may or may not indicate commercial potential.

One of these is Jane Veeder's WARPITOUT (Tolnay, 1983), an installation done for the SIGGRAPH ' 82 Art Show in Boston, July, 1982. Using the GORF hardware system as modified to run the Zgrass language, it digitized the player's image using a television camera. The player was then presented with dozens of menu-driven options enabling considerable facial warping, coloring, and so on. The player left with a Polaroid snapshot of the results. The only way to get children away from the machine was to make them agree to help adults play.

Using the same hardware, Sally Rosenthal and Copper Giloth designed a game called WRAPAROUND for the Isetan Museum Art Show opening in Tokyo, August, 1983. This game allows players to construct potentially beautiful abstract and representational animated sequences in a collage on the screen.

In general, though, industry wisdom does not think much of requiring creativity on the part of the player, because that is normally considered to be in the domain of the "hobby" market. The entertainment industry is a "consumer" industry dedicated to providing interesting diversions that " people get tired of quickly. Such distinctions are getting harder to draw : with interactive systems, however, especially on personal computers.

On the social front, several start-up groups have been proposing what is generically called the "bowling alley" concept for videogames. It involves team-played games during which people will wear company or club T-shirts and play in leagues. The newer 16-bit micros are certainly up to the networking demands of the concept. One proposal is extensively described by Cognevich (1983). Given how absolutely boring it is to wait for a turn when a good player is up, some care will have to be taken to 
make the action at least as watchable as bowling, but this should not be too hard. Envision car-racing and adventure games where the spectators can see all the screens, while the players see only their own.

The rage of 1983 is the videodisk game. The challenge is how to make it more than a simulated kiddy carnival ride. The videodisk work at M.I.T. Architecture Machine Group has had an impact much like the ELIZA program of Weizenbaum (1976). People immediately thought "Why, with my creativity (and entrepreneurial know-how) applied to that university experiment, anything is possible!" They did not recognize that both projects represented a rather evolved use of the medium and several good tricks. The videodisk business is not at the bottom of a set of easy steps; it is sitting on a rather large technological plateau right now. However, such is the case with any well-presented technology; the first-time viewers see it as amazing but simple. In any event, the first two videodisk games by Sega and Cinematronics have the video, movie, and game industries completely excited.

The big problem with videodisks, aside from content, is the branching time. Random access can take as long as several seconds, unacceptable for game play. The M.I.T. group solved this difficulty partially by having two disks so that one disk could search while the other played, but the type of zooming around offered by vector 3-D games still cannot be accomplished if the player is to control it. Additionally, two disk drives raise the hardware price to new levels. Two-headed disks are a rumored development, and are promising because they cost less than two one-headed disks.

Customizing videodisk players for special needs is no trivial matter, however; thus the pressure is on to use available consumer equipment, which does not meet real-time interaction needs. Perhaps videodisk manufacturers will realize the major market represented by videogames and configure equipment for interaction. The new compact audiodisks store digitized information with considerable error correction built into the playback. The limitations of $40 \mathrm{~K}$-byte/second transfer, however, make them inappropriate for straight analog video play, which requires about 10 times the bandwidth. No one has as yet suggested in print the use of these compact digital audio players in videogames; certainly it has been considered, however.

Perhaps the most progress will be made in the development systems. needed for future games. Unlike current ICEs and the like, which have no distribution or application outside the game industry, future programmers' and artists', work stations will have to enable solutions to problems common to the entire computer graphics field and to much of digital television production as well. Easier availability of the tools will make 
possible the use of this technology for smaller markets, as lower stakes will be acceptable. The allure of videogames can be applied to instruction, just as television can.

One further point is important. Videogames are playable by people who speak different languages. It is, in fact, the written languages that we developed in order to preserve culture and knowledge that are the barriers to communication. Interactive graphics has the capability of increasing communication worldwide, as art and music have been able to do for centuries.

\section{Conclusions}

Coin-operated videogames, from their pinball heritage to their extreme hedonistic desirability, have emerged as the black sheep, so to speak, of the interactive graphics movement. Yet, they are causing significant technological breakthroughs, especially in the area of cost/performance. We are seeing interactive fantasy emerge as a medium, and, with it, considerable development in the art of nonverbal communication. Coin-op technology quickly (within 2-3 years) passes down to personal computer systems, such that any home computer now has significantly better graphics and interactive devices than all but a few computer systems available in the lab or the office.

Knowledge of how to write games and present information through interactive animation will eventually encode itself into higher level programming structures available to subject-matter experts, teachers, inteliectuals, children, and parents. A sizable portion of the computer graphics community already exchanges information on videotape. Floppy disk is now the home computer user's way to send greetings. Animation will surely become a major form of communication once the delivery systems are ubiquitous.

Reading is, after all, a terrible waste of our human perceptual bandwidth, even if it is enjoyable. Fortunately, the richness of interaction claimed in the preceding pages can be experienced first-hand for considerably less than this book costs, even playing every game discussed here. You might want to hurry, though, before the classics disappear.

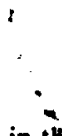

Adamo. S. (1983a). Life in the fast maze with Marty Ingels. Video Games 2, 10.

Adamo, S. (1983b). Meet Joe Video Game Player. Video Games 6, 16.

Adams, C. (1982). Governments discover new sources of revenue: Pac-Man in the parks. Wall Street Journal, Sept. 16, 1982, 29. 
Atari (1983). Advertisement. Video Games 6, 83.

Bloom, S. (1983). Video Games interview Ralph Baer. Video Games 2, 83.

Clark, J. (1982). The geometry engine. Comput. Graphics 16(3), 127.

Cognevich, V. (1983). The simulator environment. Playmeter, April 1, 1983, 32.

Crawford, C. (1982). Design techniques and ideals for computer games. Byre 12, 96.

Electronic Fun (1983). July, 1983, 98.

Eurell, B. (1983). Dragon's Lair. Video Games 7, 50.

Foley, J., and Van Dam, A. (1982). "Fundamentals of Interactive Computer Graphics," p. 491. Addison-Wesley, Reading, Massachusetts.

Hendricks, J. (1983). Interview, June 19, 1983.

Japan Times (1982). Malaysia urged to taboo video games. August 23, 1982, 13.

Jarvis, E. (1982). Picks and pans for an otherwise dull season. Video Games 10, 61.

Krier, B. (1983). Whither the video games industry? Los Angeles Times, March 11, 1983, 8.

Magi (1982). Sample reel. SIGGRAPH Video Rev. 7 (available through the author).

Mecoy, B. (1982). The art of video games. Video Games 10, 33.

Murphy, T. (1983). Interview, June 19, 1983.

Negroponte, N. (1983). La vidéo interactive. Le Film Francais, April 15, 1983, 31.

Playmeter (1982). December 15, 1982, 16.

Playmeter (1983). Bally admits to skimpy research. August 15, 1983, 18.

Schuler, B. (1983). Your show of shows. Video Games 7, 22.

Shoup, R. (1979). Color table animation. Comput. Graphics 13(2), 8.

Skow, J. (1982). Games that play people. Time, January 18, 1982, 50.

Smith, D. (1983). Playing games with cable. Video Gumes 2, 70.

Tekla, P., and Wallich, P. (1983). Design case history, the Atari video computer system. IEEE Spectrum 3(83), 45.

Tekla, P., Truxal, C., and Wallich, P. (1982). Video games: The electronic big bang. IEEE Spectrum 12(83), 22.

Tresser, N. (1982). Video Games interview Tim Skelly. Video Games 10, 74.

Tolnay, T. (1983). The, computer artist: Jane Veeder. Comput. Pictures 5, 38.

Trakin, R. (1983). Video Games interview Arnold C. Greenberg. Video Games 6, 27.

Video Games (1983). 3, 82.

Weizenbaum, J. (1976). "Computer Power and Human Reason." Freeman, San Francisco, California. 